Proceedings of the Institution of Mechanical Engineers, Part N: Journal of

Nanomaterials, Nanoengineering and Nanosystems

https://journals.sagepub.com/home/pin

Accepted Friday July $9^{\text {th }} 2021$

\title{
UNSTEADY SQUEEZING FLOW OF A MAGNETIZED NANO-LUBRICANT BETWEEN PARALLEL DISKS WITH ROBIN BOUNDARY CONDITIONS
}

\section{J.C. Umavathi ${ }^{* *}$, Sapnali Limbaraj Patil ${ }^{1}$, B. Mahanthesh ${ }^{2}$ and O. Anwar Bég ${ }^{3}$ \\ ${ }^{1}$ Department of Mathematics, Gulbarga University, Gulbarga-585 106, Karnataka, India. *Corresponding author: drumavathi@ rediffmail.com}

\begin{abstract}
${ }^{2}$ Department of Mathematics, CHRIST (Deemed to be University), Bengaluru-560029, Karnataka, India. ${ }^{3}$ Professor of Engineering Science \& Director Multi-Physical Engineering Sciences Group (MPESG), School of Science, Engineering and Environment (SEE), University of Salford, Manchester, M5 4WT, UK.
\end{abstract}

ABSTRACT: The aim of the present work is to examine the impact of magnetized nanoparticles (NPs) in enhancement of heat transport in a tribological system subjected to convective type heating (Robin) boundary conditions. The regime examined comprises the squeezing transition of a magnetic (smart) Newtonian nanolubricant between two analogous disks under an axial magnetism. The lower disk is permeable whereas the upper disk is solid. The mechanisms of haphazard motion of NPs and thermophoresis are simulated. The non-dimensional problem is solved numerically using a finite difference method in the MATLAB bvp4c solver based on Lobotto quadrature, to scrutinize the significance of thermophoresis parameter, squeezing number, Hartmann number, Prandtl number and Brownian motion parameter on velocity, temperature, nanoparticle concentration, Nusselt number, factor of friction and Sherwood number distributions. The obtained results for the friction factor are validated against previously published results. It is found that friction factor at the disk increases with intensity in applied magnetic field. The haphazard (Brownian) motion of nanoparticles causes an enhancement in thermal field. Suction and injection are found to induce different effects on transport characteristics depending on the specification of equal or unequal Biot numbers at the disks. The main quantitative outcome is that, unequal Biot numbers produce significant cooling of the regime for both cases of disk suction or injection, indicating that Robin boundary conditions yield substantial deviation from conventional thermal boundary conditions. Higher thermophoretic parameter also elevates temperatures in the regime. The nanoparticles concentration at the disk is boosted with higher values of Brownian motion parameter. The response of temperature is similar in both suction and injection cases; however, this tendency is quite opposite for nanoparticle concentrations. In the core zone, the resistive magnetic body force dominates and this manifests in a significant reduction in velocity i.e. damping. The heat buildup in squeeze films (which can lead to corrosion and degradation of surfaces) can be successfully removed with magnetic nanoparticles leading to prolonged serviceability of lubrication systems and the need for less maintenance.

KEYWORDS: Nanofluid; Parallel disks; Convective heating; Robin (mixed) boundary conditions; Brownian motion; Thermophoresis; Nanoparticles; Squeezing flow; Smart nano-lubrication. 


\section{NOMENCLATURE}

A Suction/blowing parameter

$B \quad$ Applied magnetic field

$B_{0} \quad$ Strength of axial magnetic field

$B i_{1}, B i_{2} \quad$ Biot number

Cfr Skin friction coefficient

C Concentration

$C_{h} \quad$ Concentration at the upper disk

$C_{w} \quad$ Concentration at the lower disk

$C_{p} \quad$ Specific heat

$\begin{array}{ll}D_{T} & \text { Thermophoretic diffusion coefficient }\end{array}$

$\begin{array}{ll}D_{B} & \text { Brownian motion coefficient }\end{array}$

$f \quad$ Dimensionless stream function

$h(t) \quad$ Distance between the two disks

$h_{1}, h_{2} \quad$ External heat transfer coefficients

a, $H \quad$ Positive constants

$k \quad$ Thermal conductivity

Le Lewis Number

$M \quad$ Hartmann number

Nt Thermophoretic parameter

$\mathrm{Nb} \quad$ Brownian motion parameter

Nur Nusselt number

Pr Prandtl Number

$P \quad$ Pressure

$q_{w} \quad$ Surface heat flux

$\operatorname{Re}_{r} \quad$ Reynolds number

$r / z \quad$ Space coordinate

$S \quad$ Squeeze number 


$\begin{array}{ll}\text { Shr } & \text { Sherwood number } \\ T & \text { Temperature } \\ T_{h} & \text { Temperature at the upper disk } \\ T_{w} & \text { Temperature at the lower disk } \\ T_{m} & \text { Mean fluid temperature } \\ u, w & \text { Velocity components } \\ w_{0} & \text { Suction/blowing velocity }\end{array}$

\section{Greek symbols}

$\begin{array}{ll}\eta & \text { Similarity variable } \\ \tau & \text { Heat capacity } \\ \alpha & \text { Thermal diffusivity } \\ \delta & \text { Dimensionless length } \\ \mu & \text { Dynamic Viscosity } \\ \sigma & \text { Electric conductivity } \\ \rho & \text { Density } \\ \theta & \text { Dimensionless Temperature } \\ \phi & \text { Dimensionless Concentration } \\ v & \text { Kinematic viscosity }\end{array}$

\section{INTRODUCTION}

The transient squeezing hydrodynamics of fluids in the gap between two parallel disks is finding increasing applications in liquid-metal lubrication bearing support systems for machines and roller coasters ${ }^{1}$, polymeric injection modeling ${ }^{2}$, automotive shock absorbers ${ }^{3}$, prosthetic bio tribiology ${ }^{4}$ and damping devices in power transmission". The term "squeezing transition" is habitually used in practical situations to define a fluid transition within a shrinking domain of a prearranged length. A key issue facing designers is the control of heat generated in lubrication which can induces significant damage to the approaching metal surfaces via corrosion. The modern science of squeezing lubrication theory was initiated by $\operatorname{Stefan}^{6}$ who formulated the problem for Newtonian droplet lateral motion between approaching surfaces. Later Reynolds ${ }^{7}$ 
derived the famous lubrication equation for Newtonian liquids by neglecting inertial effects. Subsequently many investigations of squeeze film hydrodynamics have been communicated for a plethora of loading conditions including oscillatory motion and with inertial effects. Important studies include Archibald ${ }^{8}$, Grimm ${ }^{9}$, Storace and Cline ${ }^{10}$, Ishizawa ${ }^{11}$ (who incorporated timedependent effects and used a perturbation method), Burrows et al. ${ }^{12}$ (who considered cavitations effects), Allaire et $a .^{13}$ (who developed finite element models for squeeze film dampers), Hamdam et al. $^{14}$ (two-phase squeezing flows) and Della and Adiletta ${ }^{15}$ (who examined 3dimensional shock absorber squeeze films).

Recently, engineers have discovered the usage of smart lubricants in squeezed/extruded films. Such intelligent lubricants respond to peripheral provocations such as magnetic or electric fields. The benefit of magneto-lubricants is that they attain a fluctuating-damping performance and permit engineers to fine tune the shuddering of machineries and other systems. Although a popular approach in magnetic squeezing flows is the derivation of an appropriate Reynolds equation with associated load capacity relations - see e.g. ${ }^{16}$, this methodology furnishes limited insight into the fluid dynamics of squeeze films. To achieve this more elegant approach is required and involves the deployment of viscous magnetohydrodynamic (MHD) models based on modifications of the classical Navier-Stokes equations. This approach also permits other electromagnetic phenomena to be considered including magnetic induction, leakage, ion slip etc. An important study of MHD squeezing flow was presented by Hughes and Elco ${ }^{17}$ who considered one rotating disk and a stationary one for two field configurations, and noted that frictional torque on the rotating disk may be eliminated in both cases via precise electrical current deployment at the electrodes. Subsequently many studies have been communicated concerning magnetohydrodynamic squeeze flow boundary value problems with a variety of analytical and numerical methods and with heat and/or species diffusion effects. Chandrasekhara et $a l .{ }^{18}$ considered wall hydrodynamic slip and suction effects on MHD squeeze film under an axial magnetic field. Verma ${ }^{19}$ generalized earlier models to consider an oblique magnetic field for squeezing flow between a rigid impermeable rectangular plate and a porous plate, observing that the approach time of the upper disk is prolonged relative to non-magnetic flows and load capacity is therefore enhanced. Siddiqui et $a .^{20}$ investigated the Newtonian squeeze flow between two parallel flat plates. Ghadikolaei et $a l .{ }^{21}$ used power series expansions and RungeKutta quadrature to compute the Ohmic dissipation effect on unsteady non-Newtonian 
hydromagnetic squeezing flow in a stretching parallel plate system with heat and mass transfer. Zueco and Bég ${ }^{22}$ deployed electrothermal network simulation to simulate the electrically conducting squeeze film flow amongst spinning disks with Batchelor number and electromagnetic induction effects. Mahanthesh et $a .^{23}$ studied the hydromagnetic dusty squeezing flow in a rotating dual disk system with wall suction/injection. Bég et al. ${ }^{24}$ used the Adomian decomposition and Nakamura tridiagonal difference methods to compute the induced magnetic field and tangential velocity components in rotating disk squeeze film flow in a smart prosthetic knee lubrication system. Hayat et al. ${ }^{25}$ computed the transient viscoelastic magnetic squeezing flow between dual disks with wall suction/blowing effects. Shamshuddin et al. ${ }^{26}$ used MATLAB bvp4c quadrature to compute chemical corrosion inhibition effects in transient magnetohydrodynamic bioconvection squeezing flow. Arain et al. ${ }^{27}$ (2-Ref-3) dealt with the flow behavior betwixt a pair of rotating circular plates filled with Carreau fluid under the suspension of nanoparticles and motile gyrotactic microorganisms in the presence of generalized magnetic Reynolds number. They concluded that the shear-thinning fluid viscosity was decreased with shear strain due to its high velocity compared to the Newtonian and shearthickening case.

Kazzar et $a .^{28}$ studied transient squeezing flow of a ferrofluid between expanding/contracting non-parallel plates. Very recently Bég et al. $^{29}$ used the variational parameter method (VPM) to investigate the impact of thermal relaxation (non-Fourier heat flux) and Ohmic dissipation on 3-dimensional squeezing flow between electromagnetic sensor surfaces for earthquake damping control. Zhang et al. ${ }^{30}$ (2-Ref2) examined the electromagnetohydrodynamic behavior of a third-grade non-n-n-Newtonian fluid, flowing between a pair of parallel plates in the presence of electric and magnetic fields. They found that the DarcyBrinkman-Forchheimer parameter and the third-grade fluid model parameter retards, whereas both parameters have an inverse effect on the temperature profile. Shahid et al. ${ }^{31}$ scrutinized the incompressible steady flow with temperature-dependent viscosity of magnetohydrodynamics nanofluid through a vertically stretched porous sheet. The velocity reduces by enlarging the values of viscosity parameter, permeability parameter, Forchheimer parameter, and Hartmann number and boosts momentum boundary layer thickness in the stretchable nanofluid sheet. 
Since heat generation is a critical issue in lubrication systems, engineers have actively tested new fluid technologies to cope with this. Nanofluids refer to colloidal suspensions of nanoparticles (NPs) dispersed in base fluids (water, greases, DI water, ethylene glycol, silicon oil and poly- $\alpha$-olefin oil (PAO) etc) (see $\mathrm{Choi}^{32}$ ). Generally nanoparticles (NPs) are synthesized from metals $(\mathrm{Cu}, \mathrm{Ag})$, Carbides $(\mathrm{Sic})$, oxides $\left(\mathrm{TiO}_{2}, \mathrm{Al}_{2} \mathrm{O}_{3}\right)$ or non-metallic carbon nanotubes. Buongiorno $^{33}$ identified the random (haphazard) Brownian motion of NPs and thermophoresis as dominant mechanisms contributing to the enhanced convective heat transport observed in nanofluids. Many excellent and detailed laboratory investigations of the improved performance of lubricants designed with nanoparticles have also been reported subsequently. Key works in this regard include Hwang et $a .^{34}$ (with a focus on thermal conductivity), Chen et al. ${ }^{35}$ (examining dispersion characteristics in oil base liquids) and Ghaednia et al. ${ }^{36}$ (copper oxide nanoparticles with different shapes). Bég et al. ${ }^{37}$ conducted a rigorous experimental study of the enhanced lubrication properties of metal and metallic oxide nanoparticle (NP)-doped waterbased mud drilling fluids, noting the significant improvements in circulation, torque and drag, elimination of sticking problems and bit balling achieved with titanium, zinc and tin compared with conventional silica nanoparticles. Further studies of nanoparticles in lubrication include Pendleton $^{38}$ in orthopaedics, Nicoletti ${ }^{39}$ for journal bearings, Harta et al. ${ }^{40}$ on high temperature zinc oxide oil nano-tribology, $\mathrm{Wu}$ et al. ${ }^{41}$ explored $\mathrm{CuO}, \mathrm{TiO}_{2}$, and diamond nano-particles. $\mathrm{Hu}$ et $a l .{ }^{42}$ considered magnesium borate nanoparticles. Squeeze film flows of nanofluids have also received some attention. Interesting studies include Hashimi et al. ${ }^{43}$ (on Buongiorno nanoliquids), Das et $a l .{ }^{44}$ (who have also considered wall slip) and Dib et al. $^{45}$ (who have included time-dependent effects).

Khan et al. ${ }^{46}$ (2021) addressed the bioconvective Oldroyd-B nanofluid transport over a convectively heated configuration. It was observed that variation in relaxation time constant increased the velocity profile which was more progressive in the presence of slip effects. The presence of slip factor improved the heat and mass transportation more effectively. Hosseinzadeh et al. ${ }^{47}$ investigated micropolar magnetohydrodynamics (MHD) fluid flow along a vertical plate. Their results indicated that for water-based fluids, the temperature profile of lamina-shaped nanoparticles was $38.09 \%$ higher than brick-shaped nanoparticles. Rostami et al. $^{48}$ (2020) simulated the $\mathrm{Al}_{2} \mathrm{O}_{3}$-Ethylene Glycol nanofluid convective heat transfer in a porous medium 
under the impact of magnetic field. They noted that the local Nusselt number was elevated with increasing nanoparticle volume fraction and Rayleigh number whereas it was reduced with greater Hartmann (magnetic) number. Hosseinzadeh et al. ${ }^{49}$ investigated the cross-fluid flow containing gyrotactic microorganisms and nanoparticles on a three-dimensional horizontal cylinder with viscous dissipation and radial magnetic field. They observed that when the Brownian motion parameter varies from 0.1 to 0.4 , the concentration of nanoparticle reduces approximately $80.43 \%$. Furthermore, with the change of bioconvection Lewis number from 0.2 to 0.5 , it was observed that the concentration of the microorganisms reduced by about $78.38 \%$.

The new generation of magnetic nano-lubricants provides a dual mechanism for both heat dissipation (via removal in continuous feed circuits) and smart control via magnetic fields. They comprise suspensions of magnetic nanoparticles (NPs) distributed in base fluids such as Trimethylolpropane Trioleate base oil ${ }^{50}$ and magnetite $\left(\mathrm{Fe}_{3} \mathrm{O}_{4}\right)$ nanoparticles ${ }^{51-53}$. An inspection of the literature has revealed that despite the extensive experimental work conducted on magnetic nano-lubricant tribology and squeeze films, relatively few theoretical and /or numerical simulations of such flows have been reported. Bég et al. ${ }^{54}$ presented an analysis of unsteady magnetic nanofluid squeezing flow using Buongiorno's model and a B-spline collocation technique. They noted the enhanced load capacity achieved with stronger magnetic fields and smaller nanoparticles (higher Brownian motion effect). Hosseinzadeh et al. ${ }^{55}$ experimented on the effect of two different fins and hybrid nanoparticles on the solidification process in a triplex latent heat thermal energy storage system. Their results showed that while the combined usage of nanoparticles and tree-like fins gives the best result by lowering the solidification time by $78 \%$ compared to a bare tube, tree-like fins achieve the best performance taking 1700s for solidification followed by rectangular fins with $3500 \mathrm{~s}$ if nanoparticles are out of reach.

Lahmar et $a l .{ }^{56}$ used a differential transform method and the Tiwari-Das model to determine the influence of volume fraction of magnetite $\left(\mathrm{Fe}_{3} \mathrm{O}_{4}\right)$ nanoparticles, Hartmann number, squeeze number, magnetic field inclination and variable thermal conductivity on load capacity in transient squeezing of magnetic nanofluids. They noted that higher percentage doping and higher thermal conductivity achieve the desired thermal enhancement whereas the opposite effect is induced with oblique magnetic field. Ahmed et al. ${ }^{57}$ deployed an Adomian technique to compute the effects of radiative flux and viscous heating on electromagnetic CNT 
(carbon nanotube)-water nanofluid squeezing flow in a dual Riga magnetic sensor plate system. They observed that skin friction is reduced with greater squeeze number and magnetic field strengths and that local rate of heat transfer to the disks from the nanofluid are suppressed with greater radiation heat transfer. Vajravelu et al. ${ }^{58}$ derived semi-numerical solutions for variable fluid property and momentum/temperature slip effects on transient magnetic nanofluid squeezed/extruded flow between two parallel spongy disks. Hosseinzadeh et al. ${ }^{59}$ (2020) (1-Ref6) simulated numerically the effect of internal fins along with hybrid nano-particles on solid process in a star shape triplex Latent Heat Thermal Energy Storage System. They concluded that the combination of fins and HNPs gives rise to the best possible result, with the outcomes registering approximately 5 times faster solidification rate than pure PCM (Phase Change Material).

A scrutiny of the literature has shown that thus far no magnetic tribological nanofluid squeezing flow studies have incorporated convective heat interchange at the disk walls. Since a prime focus of NPs is to improve in the removal of heat from lubrication systems, it is judicious to examine cooling/heating of the wall via the convective heat exchange between the surface and the nanofluid. Aziz ${ }^{60}$ studied the convective heat exchange in thermal flow from a flat plate, observing the considerable elevation in temperatures. Uddin et al. ${ }^{61}$ studied convective heating effects on slip magnetohydrodynamic nanofluid dynamics from radially extending/contracting sheets observing a significant modification in both Nusselt and Sherwood numbers. Pattnaik et $a l{ }^{62}$ studied the combined impact of convective heating, exponential heat source and Ohmic electrothermal dissipation on magnetized micropolar nanoliquid over an extended plate with shooting quadrature. Uddin et al. ${ }^{63}$ analyzed the composite effects of conjugate wall conduction and convective boundary heating on magnetized thermo-solutal layer flow from a non-linear elongating plate with hydrodynamic/thermal/concentration slip and radiative heat transfer. Hydrothermal evaluation of hybrid nanofluid with a water-ethylene glycol (50-50\%) base fluid containing $\mathrm{MoS}_{2}-\mathrm{TiO}_{2}$ hybrid nanoparticles, in an octagon with an elliptical cavity in the middle, was performed by Hosseinzadeh et al. ${ }^{64}$ Their results illustrated that with an augmentation in Rayleigh number from 10 to 100, the average Nusselt number was improved by about $61.82 \%$. Hosseinzadeh et al. ${ }^{65}$ studied the flow of a mixture of water and ethylene glycol (50-50\%) with hybrid nanoparticles (MWCNT-Ag) over a vertical stretching cylinder. The 
results showed that, for hybrid nanoparticles, lamina and spherical geometries have the largest difference; the lamina is smaller by $6 \%$. They also showed that with increasing Hartmann number, the radial velocity was reduced by $9.68 \%$ for hybrid nanoparticles.

Extensive analysis of multi-physical heat and mass transfer problems using Robin boundary conditions has been conducted in recent years by Umavathi and co-workers. These studies have explored porous media ${ }^{66}$, cross diffusion in mixed convection ${ }^{67}$, triple diffusion in ducts ${ }^{68}$ and micropolar channel flows ${ }^{69}$. However, the transient magnetohydrodynamic squeezing flow of nano-lubricants with Robin boundary conditions imposed at the disks remains an open question in the literature. This is the focus of the current study, viz, to investigate for the first time the effects of Robin boundary condition on time-dependent squeezing flow of Newtonian magnetic nanofluid lubricants under transverse (axial) time-dependent magnetic field. A further feature of the current study is the inclusion of suction/injection at the lower disk. The normalized, multidegree nonlinear boundary value problem is solved numerically with a finite difference approach in the MATLAB bvp4c routine featuring three-stage Lobatto IIIa formulae ${ }^{70}$. A detailed study is conducted of the influence of key parameters (e.g. magnetic field, Brownian motion, equal and unequal Biot numbers for convective boundary heating etc) on the velocity, temperature, nanoparticle concentration and skin friction distributions in the regime. Verification of the MATLAB solutions with the homotopy solutions of Hashimi et l. $^{43}$ is included. The simulations are relevant to modern magneto-nano-tribological systems.

\section{MATHEMATICAL MODEL FOR MAGNETIC NANO-LUBRICANT SQUEEZING FLOW}

Time-dependent hydromagnetic squeezed/extruded flow of a magnetized nanofluid-lubricant is considered in the layer intercalated between two parallel, insulated, electrically non-conducting disks separated by a time-dependent distance $h(t)=H(1-a t)^{1 / 2}$. A time-based magnetic field $B(t)=B_{0}(1-a t)^{-1 / 2}$ is applied in the axial direction i.e. transverse to the disks (see Fig. 1). The disk located at $z=h(t)$ moves away from or towards the immovable disk located at $\mathrm{z}=0$ with a velocity $d h / d t$. The Buongiorno theory for nanofluids and convective heating (Robin boundary condition) for temperature are utilized. Hall and Maxwell displacement currents and induction effects are ignored. 


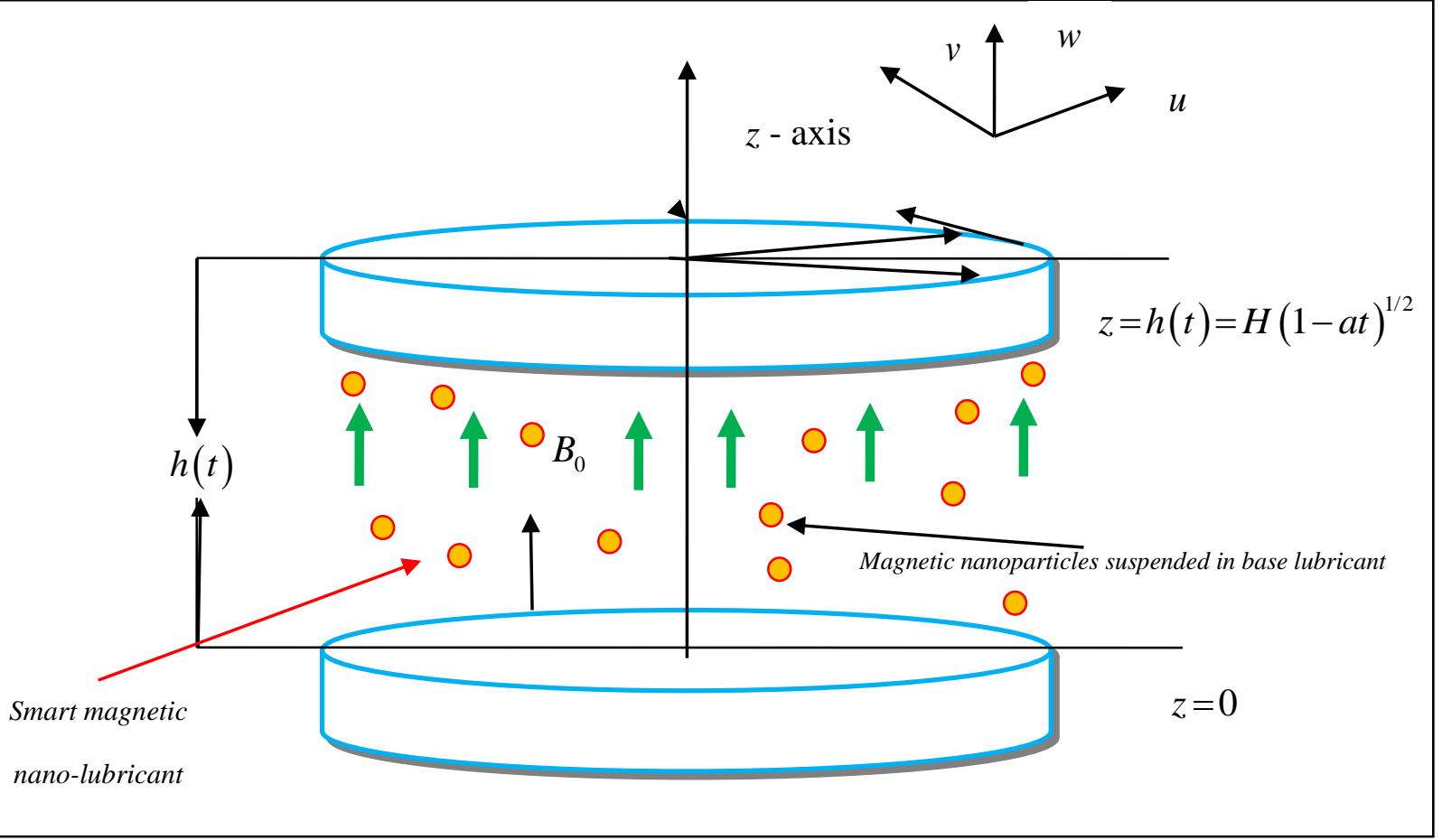

Figure 1. Schematic for unsteady magnetic nano-lubricant squeeze flow

The conservation equations in an axisymmetric coordinate system $(r, z)$ are (following Hayat et al. ${ }^{25}$ and Hashmi et al. ${ }^{43}$ )

$$
\begin{gathered}
\frac{\partial u}{\partial r}+\frac{u}{r}+\frac{\partial w}{\partial r}=0 \\
\frac{\partial u}{\partial t}+u \frac{\partial u}{\partial r}+w \frac{\partial u}{\partial z}=\frac{-1}{\rho} \frac{\partial P}{\partial r}+v\left[\frac{\partial^{2} u}{\partial r^{2}}+\frac{\partial^{2} u}{\partial z^{2}}+\frac{1}{r} \frac{\partial u}{\partial r}-\frac{u}{r^{2}}\right]-\frac{\sigma}{\rho} B^{2}(t) u \\
\frac{\partial w}{\partial t}+u \frac{\partial w}{\partial r}+w \frac{\partial w}{\partial z}=\frac{-1}{\rho} \frac{\partial P}{\partial z}+v\left[\frac{\partial^{2} w}{\partial r^{2}}+\frac{\partial^{2} w}{\partial z^{2}}+\frac{1}{r} \frac{\partial w}{\partial r}\right] \\
\frac{\partial T}{\partial t}+u \frac{\partial T}{\partial r}+w \frac{\partial T}{\partial z}=\alpha\left[\frac{\partial^{2} T}{\partial r^{2}}+\frac{1}{r} \frac{\partial T}{\partial r}+\frac{\partial^{2} T}{\partial z^{2}}\right]+\tau\left[D\left(\frac{\partial C}{\partial r} \frac{\partial T}{\partial r}+\frac{\partial C}{\partial z} \frac{\partial T}{\partial z}\right)+\frac{D_{T}}{T_{m}}\left(\left(\frac{\partial T}{\partial r}\right)^{2}+\left(\frac{\partial T}{\partial z}\right)^{2}\right)\right] \\
\frac{\partial C}{\partial t}+u \frac{\partial C}{\partial r}+w \frac{\partial C}{\partial z}=D_{B}\left[\frac{\partial^{2} C}{\partial r^{2}}+\frac{1}{r} \frac{\partial C}{\partial r}+\frac{\partial^{2} C}{\partial z^{2}}\right]+\frac{D_{T}}{T_{m}}\left[\frac{\partial^{2} T}{\partial r^{2}}+\frac{1}{r} \frac{\partial T}{\partial r}+\frac{\partial^{2} T}{\partial z^{2}}\right]
\end{gathered}
$$


The prescribed boundary conditions are:

$$
\begin{array}{ll}
u=0, w=\frac{d h}{d t},-\left.k \frac{\partial T}{\partial z}\right|_{z=h(t)}=h_{2}\left[T(r, z(t))-T_{h}\right], C=C_{h} . & \text { at } z=h(t) \\
u=0, w=\frac{-w_{0}}{\sqrt{1-a t}},-\left.k \frac{\partial T}{\partial z}\right|_{z=0}=h_{1}\left[T_{w}-T(r, 0)\right], C=C_{w} . \quad \text { at } z=0
\end{array}
$$

Here the following notation applies: $(u, w)$ velocities along the $(r, z)$ directions, $\rho$ - density, $v$ - dynamic viscosity, $\sigma$ - electrical conductivity, $P$ - pressure, $T$-temperature, $C$ - NPs concentration, $\alpha$ - thermal diffusivity, $\left(D_{B}, D_{T}\right)$ - coefficients of (Brownian haphazard motion, thermophoretic thermal diffusion), $T_{m}$ - mean fluid temperature $\left(T_{h}, T_{w}\right)$ - temperature at (upper disk, lower disk), $\left(C_{h}, C_{w}\right)$ - concentration (at upper disk, lower disk), $w_{0}$ - suction/blowing velocity, $k$ - thermal conductivity, $\left(h_{1}, h_{2}\right)$ - external heat transfer coefficients and $\tau$-the ratio of effective heat capacity of the magnetic NPs to that of lubricant. The following similarity transformations are invoked:

$$
\begin{aligned}
& u=\frac{a r}{2(1-a t)} f^{1}(\eta), \quad w=\frac{a H}{\sqrt{1-a t}} f(\eta), \eta=\frac{z}{H \sqrt{1-a t}}, \\
& B(t)=\frac{B_{0}}{\sqrt{1-a t}}, \theta=\frac{T-T_{h}}{T_{w}-T_{h}}, \quad \phi=\frac{C-C_{h}}{C_{w}-C_{h}}
\end{aligned}
$$

Eliminating pressure gradient from equations (2) and (3), the partial differential conservations equations readily reduce to the subsequent trio of nonlinear equations for momentum, energy and nanoparticle concentration (equation (1) is satisfied inevitably and the equation (3) vanished):

$$
\begin{gathered}
f^{\prime \prime \prime \prime}-S\left(\eta f^{\prime \prime \prime}+3 f^{\prime \prime}-2 f f^{\prime \prime \prime}\right)-M^{2} f^{\prime \prime}=0 \\
\theta^{\prime \prime}+\operatorname{Pr} S\left(2 f \theta^{\prime}-\eta \theta^{\prime}\right)+\operatorname{Pr} N b \theta^{\prime} \phi^{\prime}+\operatorname{Pr} N t \theta^{\prime 2}=0 \\
\phi^{\prime \prime}+\operatorname{LeS}\left(2 f \phi^{\prime}-\eta \phi^{\prime}\right)+\frac{N t}{N b} \theta^{\prime \prime}=0
\end{gathered}
$$

The non-dimensional boundary conditions $(6 a, b)$ emerge as: 


$$
\begin{aligned}
& f(0)=A, f^{\prime}(0)=0, \theta^{\prime}(0)=B i_{1}[\theta(0)-1], \phi(0)=1, \\
& f(1)=\frac{1}{2}, f^{\prime}(1)=0, \theta^{\prime}(1)=B i_{2}[\theta(1)], \phi(1)=0 .
\end{aligned}
$$

Here $L e=\frac{v}{D_{B}}$ is Lewis number, $A=\frac{w_{0}}{a H}$ is the suction/blowing parameter at the lower disk (for suction $A>0$ and for blowing $A<0$ - note the upper disk is impermeable), $N b=\frac{(\rho C)_{p} D_{B}\left(C_{w}-C_{h}\right)}{(\rho C)_{f} v}$ is Brownian motion parameter, $S=\frac{a H^{2}}{2 v}$ is the squeezing number ( $S>0$ implies the lower disk moving towards the upper disk and $S<0$ implies the upper disk descending towards the lower disk), $M=\sqrt{\frac{\sigma B_{0}^{2} H^{2}}{v}}$ is the Hartmann (magnetic body force) number, $\quad \operatorname{Pr}=\frac{v}{\alpha}$ is Prandtl number, $N t=\frac{(\rho C)_{p} D_{T}\left(T_{w}-T_{h}\right)}{(\rho C)_{f} T_{m} v}$ is thermophoresis parameter, $B i_{1}$ is lower disk Biot number and $B i_{2}$ is upper disk Biot number (which simulate convective heating effects). The important quantities in lubrication design are the skin friction factor $C_{f r}$ at the upper disk, Nusselt number Nur and Sherwood number Shr which are defined, respectively, as follows:

$$
C_{f r}=\frac{\left.\tau_{r z}\right|_{z=h(t)}}{\rho\left(\frac{-a H}{2(1-a t)^{1 / 2}}\right)^{2}}, N u r=\frac{H q_{w}}{k\left(T_{w}-T_{h}\right)}, S h r=\frac{H j_{w}}{D_{B}\left(C_{w}-C_{h}\right)}
$$

Here $\tau_{r z}=\left.\mu\left(\frac{\partial u}{\partial z}+\frac{\partial w}{\partial r}\right)\right|_{z=h(t)}, q_{w}=-\left.k\left(\frac{\partial T}{\partial z}\right)\right|_{z=h(t)}, j_{w}=-\left.D_{B}\left(\frac{\partial C}{\partial z}\right)\right|_{z=h(t)}$ are respectively the upper disk shear stress, heat flux and nanoparticle mass flux. In terms of the transformation variables given in Eqn. (6), the above relations yields the appropriate non-dimensional expressions for upper disk skin friction, $f^{\prime \prime}(1)$, reduced Nusselt number, Nur and reduced Sherwood number, Shr viz: 
$\frac{H^{2}}{r^{2}} \operatorname{Re}_{r} C_{f r}=f^{\prime \prime}(1) \quad, N u r=(1-a t)^{\frac{1}{2}} N u=-\theta^{\prime}(1), \quad S h r=(1-a t)^{\frac{1}{2}} \operatorname{Sh}=-\phi^{\prime}(1)$

Here $\operatorname{Re}_{r}=\frac{r a H(1-a t)^{1 / 2}}{2 v}$ is local Reynolds number based on the disk gap separation distance, $H(t)$. The $7^{\text {th }}$ order multi-degree ordinary differential 2-point boundary value problem described in equations (9)-(10) with boundary conditions (11a, b) is strongly coupled and nonlinear. A numerical solution is therefore elected and elaborated next.

\section{MATLAB NUMERICAL SOLUTIONS}

Equations (8)-(11) have been solved by the bvp4c routine in MATLAB. The bvp4c solver is based on a finite difference scheme that includes the three-stage Lobatto IIIa formulae. It is a collocation procedure and provides $\mathrm{C}^{1}$-continuous solutions which have fourth-order accuracy that is continued uniformly in an integration interval. The Mesh choice and error control are centred on the residual of the continuous solution. Mesh points are utilized in collocation procedure to discretize the solution interval. Subsequent algebraic equations of boundary conditions are treated by solver and collocation conditions enforced on all the subintervals. Later, solver computes the error on each subinterval. If solution doesn't meet the criteria of tolerance, the solver utilized the mesh repeatedly. Points must be specified on the initial mesh, along with an initial approximation of the solution at the mesh points. The Lobatto polynomial $\operatorname{Lo}(n, x)$ is:

$$
\operatorname{Lo}(n, x)=n *(P(n-1, x)-x * P(n, x))
$$

where $P(n, x)$-Legendre polynomial, $n$-order, $x$ is a real value between -1 and +1 .

The $L o(n, x)$ has degree $n+1$, and is zero at $x=-1$ and $x=+1$. The bvp4c Lobatto computational methodology has been rigorously verified in several recent studies including Zohra et al. ${ }^{70}$ (on anisotropic slip effects in spinning cone thermosolutal convection), Uddin et al. ${ }^{71}$ (on gyrotactic nanofluid convection boundary layers) and Bég et al. $^{72}$ (on swirling mass diffusion from a downward pointing cone in orthotropic high-permeabliity media). To further verify the accuracy of the MATLAB solutions, in the absence of Robin boundary conditions, direct comparison is made with the homotopy analysis method (HAM) solutions of Hashmi et al. ${ }^{43}$ (who employed isothermal wall conditions) and documented in Table 1. Since the momentum Equation (8) is 
independent of temperature it follows that therefore either Robin boundary conditions or isothermal wall conditions will not affect skin friction values. A very good correlation testifies to the validity of the MATLAB methodology.

Table 1. Comparison table for skin friction coefficient $f^{/ /}(1)$ for different values of $M$ and $S$ when $A=2, P=L e=1, N b=N t=0.1$.

\begin{tabular}{|c|c|c|c|c|}
\hline$M$ & $S$ & \multicolumn{2}{|c|}{$f^{/ /}(1)$} & \\
\hline & & MATLAB & MATLAB & Reference [43] \\
& & $B i_{1}=B i_{2}=10$ & $B i_{1}=1.0, B i_{2}=10$ & HAM \\
\hline 0 & 1 & 7.53313247 & 7.53313247 & 7.53316579 \\
\hline 2 & 1 & 8.26383886 & 8.26384197 & 8.26387231 \\
\hline 3 & 1 & 9.09725938 & 9.09726618 & 9.09732572 \\
\hline 5 & 1 & 11.34929888 & 11.34931578 & 11.3492890 \\
\hline 1 & 0.1 & 8.97546290 & 8.97546290 & 8.97552394 \\
\hline 1 & 0.5 & 8.34917873 & 8.34916801 & 8.34924578 \\
\hline 1 & 1 & 7.72190940 & 7.72191376 & 7.72194601 \\
\hline 1 & 2 & 6.94081636 & 6.94082584 & 6.94077326 \\
\hline
\end{tabular}

\section{RESULTS AND DISCUSSION}

Here the MATLAB results for velocity $\left(f^{\prime}(\eta)\right)$, temperature $(\theta(1))$ and the nanoparticle species concentration $(\theta(\eta))$ are visualized in graphical form in Figures 2a,b - 12a,b. Figures are presented for the cases of suction $A>0$ and blowing $A<0$ both for equal and unequal Biot numbers. In all subsequent discussion, the acronym BEUBN is employed for brevity to denote "both equal and unequal Biot numbers". Generally, the case of approaching disks $(S)$ is considered. All data is prescribed based on realistic values of magnetic nano-lubricants as provided in multiple sources including Kotia et al. ${ }^{53}$. 


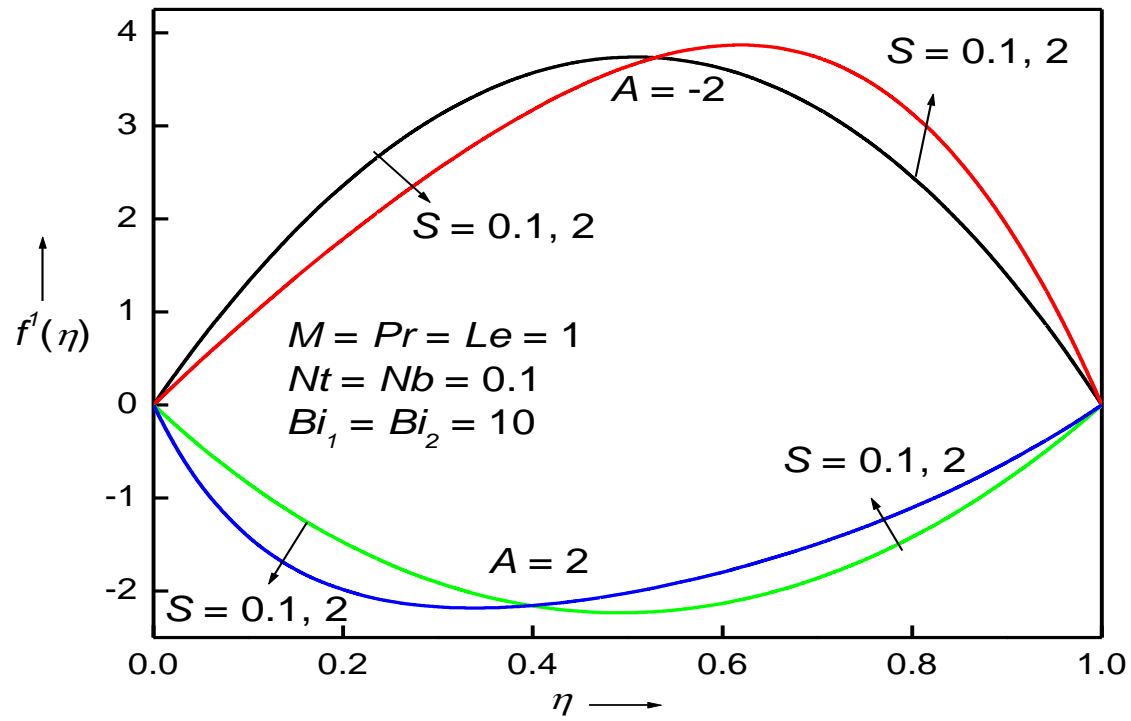

Figure 2a. Influence of $S$ on $f^{l}(\eta)$ for equal Biot numbers.

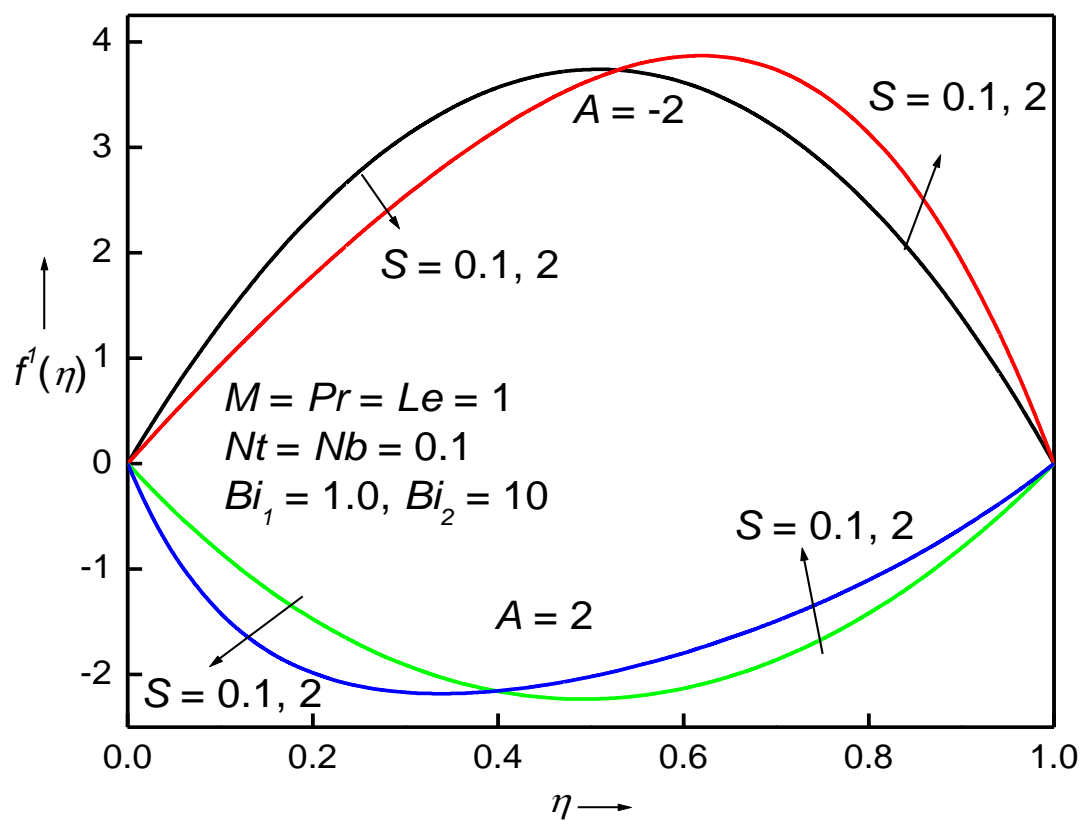

Figure 2b. Influence of $S$ on $f^{l}(\eta)$ for unequal Biot numbers. 


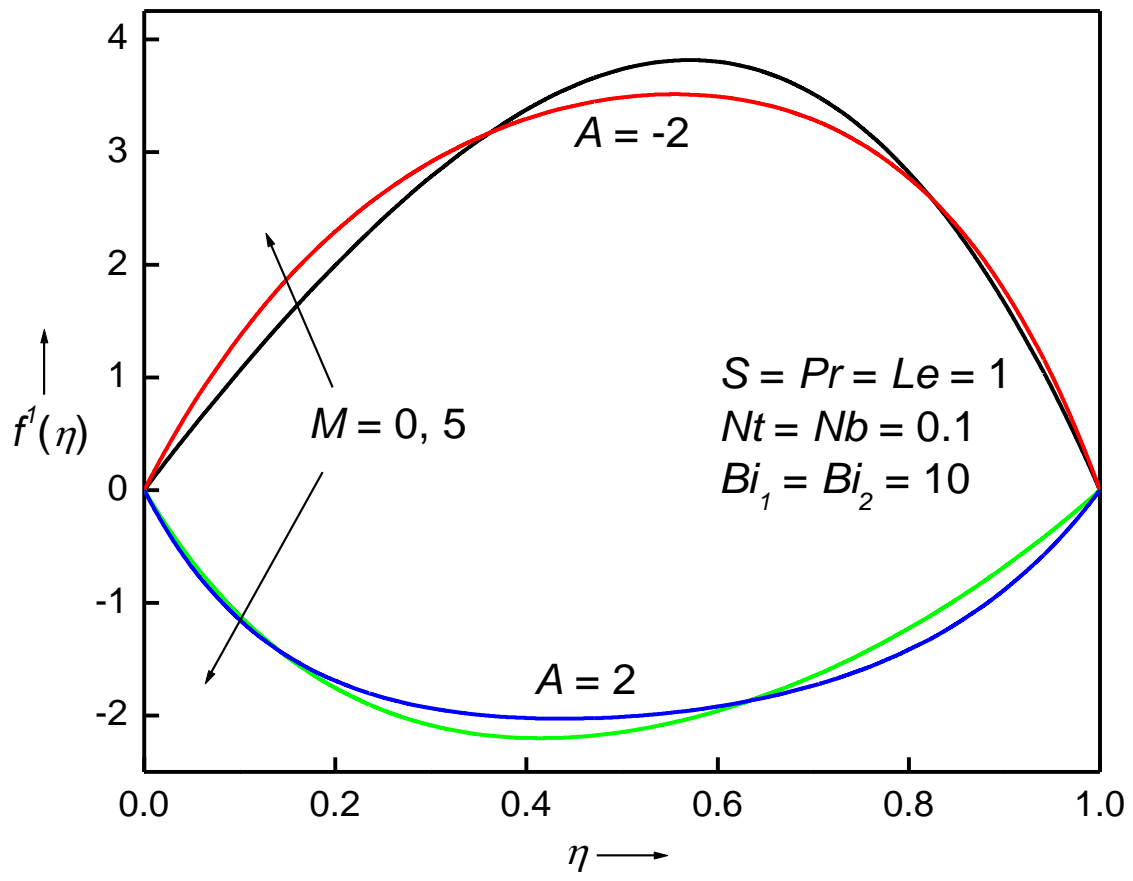

Figure 3a. Influence of $M$ on $f^{d}(\eta)$ for equal Biot numbers.

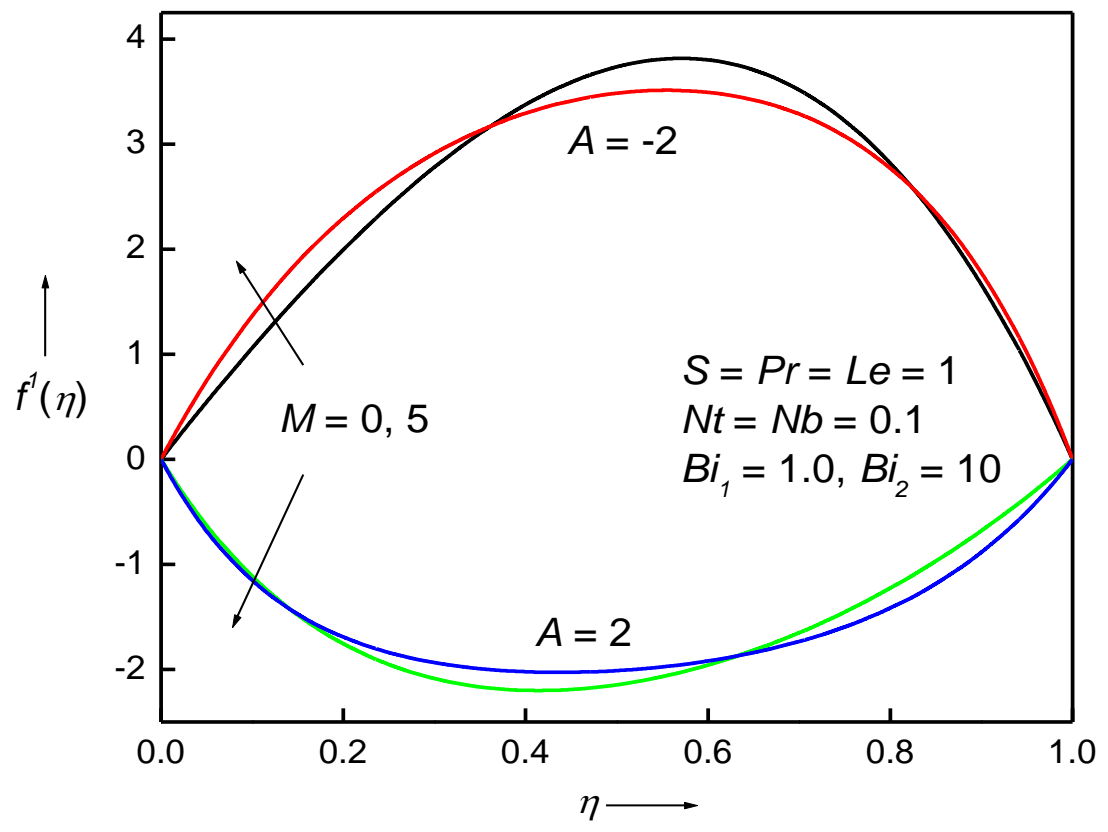

Figure $3 \mathrm{~b}$. Influence of $M$ on $f^{\prime}(\eta)$ for unequal Biot numbers. 


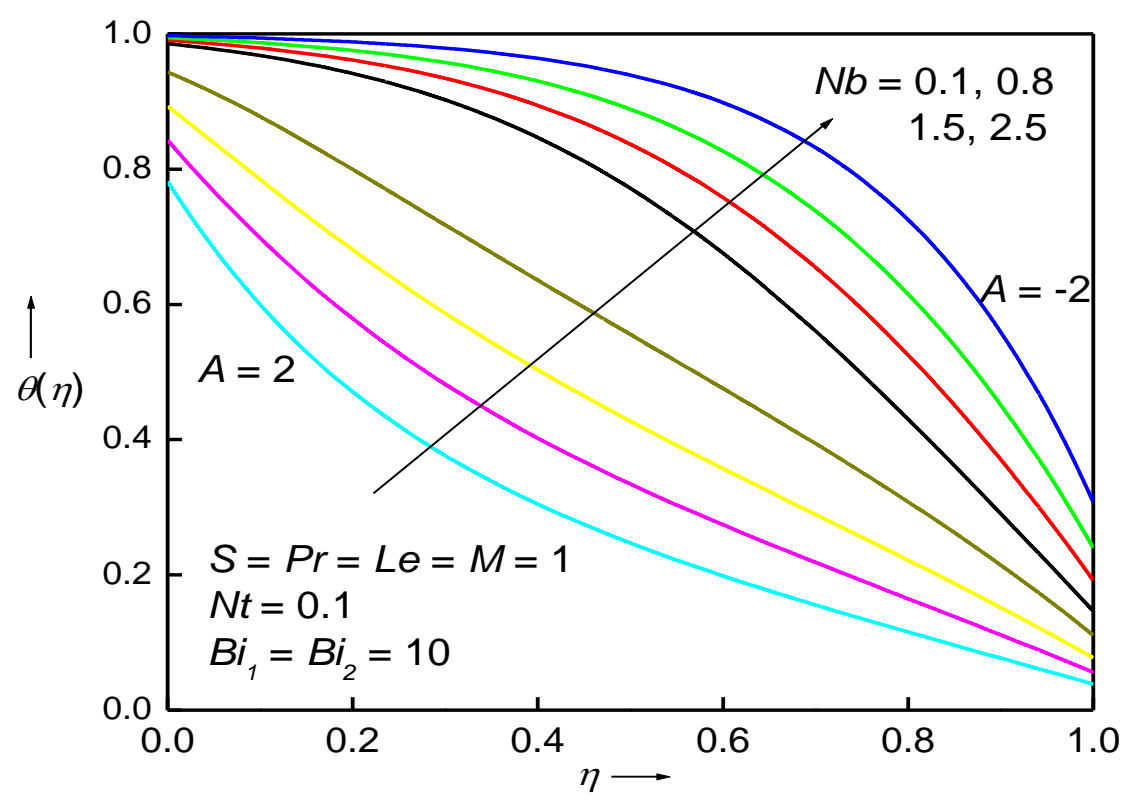

Figure 4a. Influence of $N b$ on $\theta(\eta)$ for equal Biot numbers.

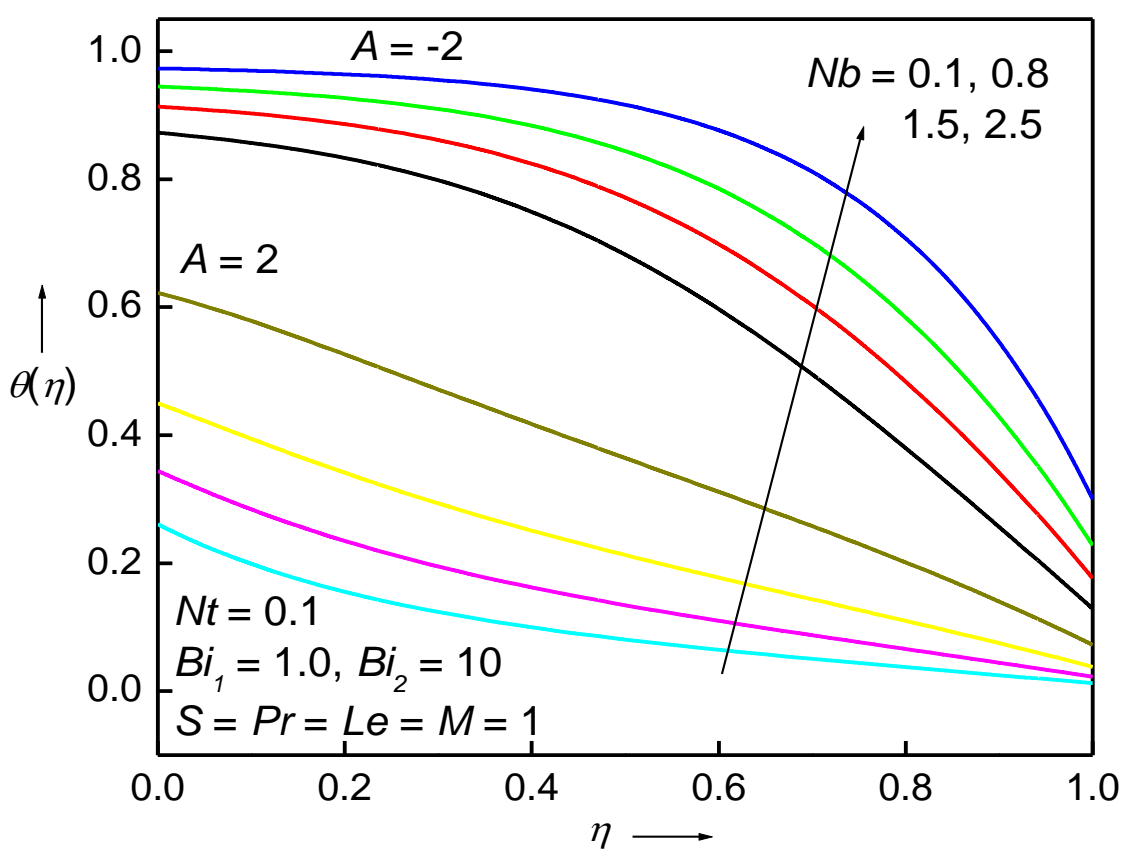

Figure $4 \mathrm{~b}$. Influence of $N b$ on $\theta(\eta)$ for unequal Biot numbers. 


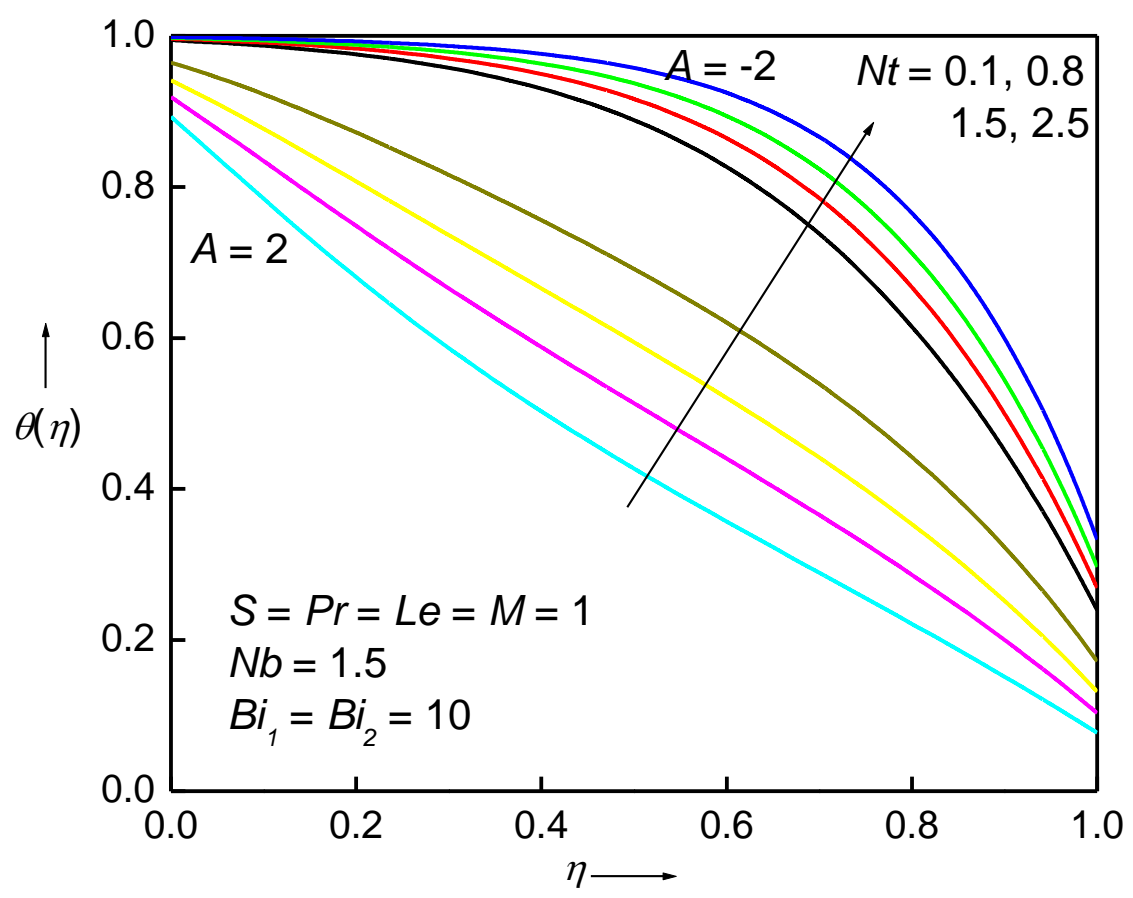

Figure 5a. Influence of $N t$ on $\theta(\eta)$ for equal Biot numbers.

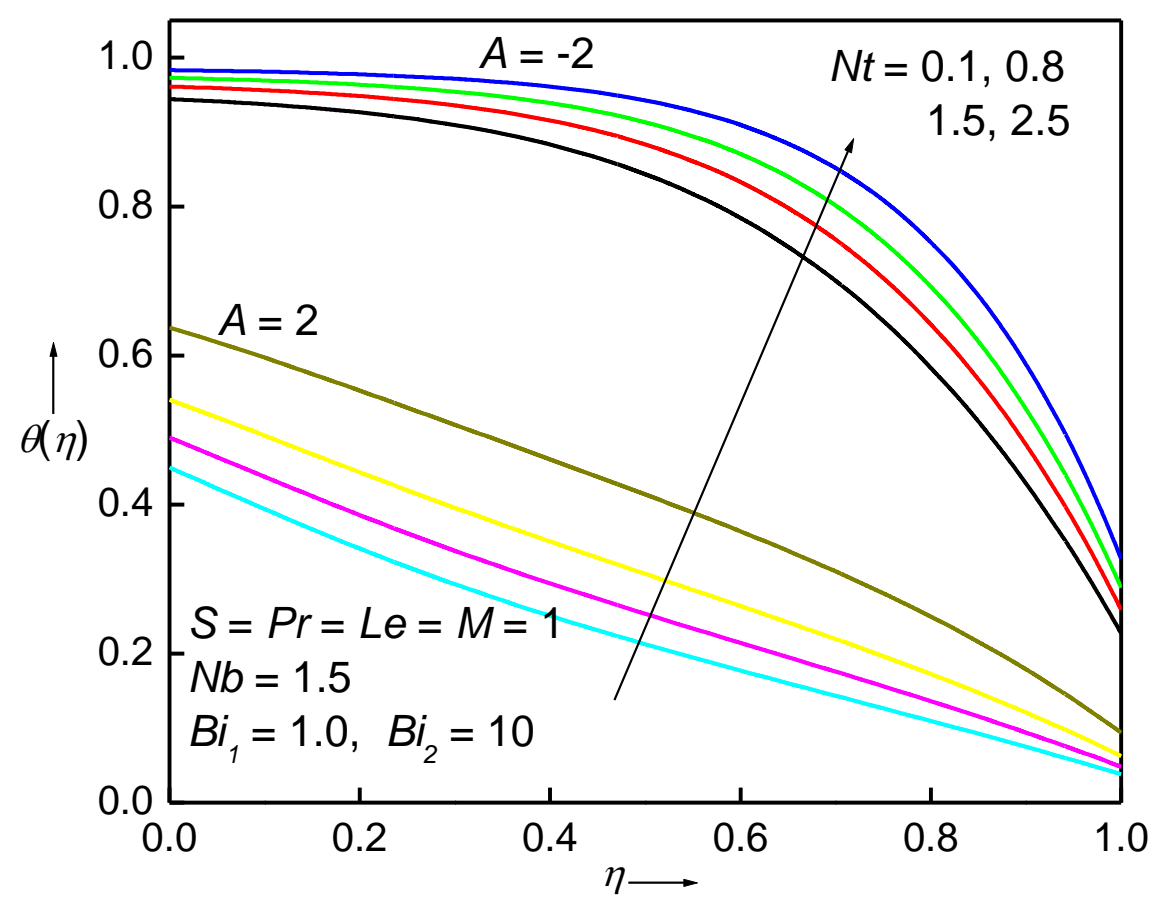

Figure $5 \mathrm{~b}$. Influence of $N t$ on $\theta(\eta)$ for unequal Biot numbers. 


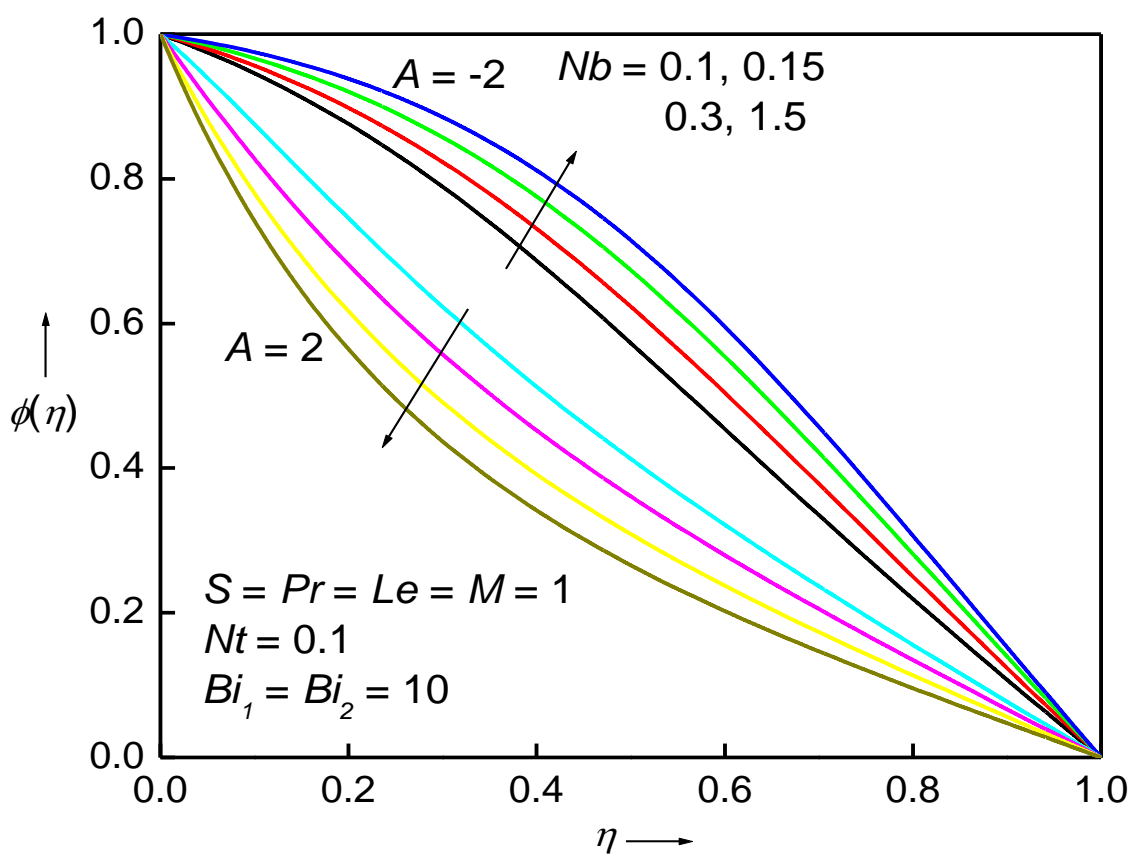

Figure 6a. Influence of $N b$ on $\phi(\eta)$ for equal Biot numbers.

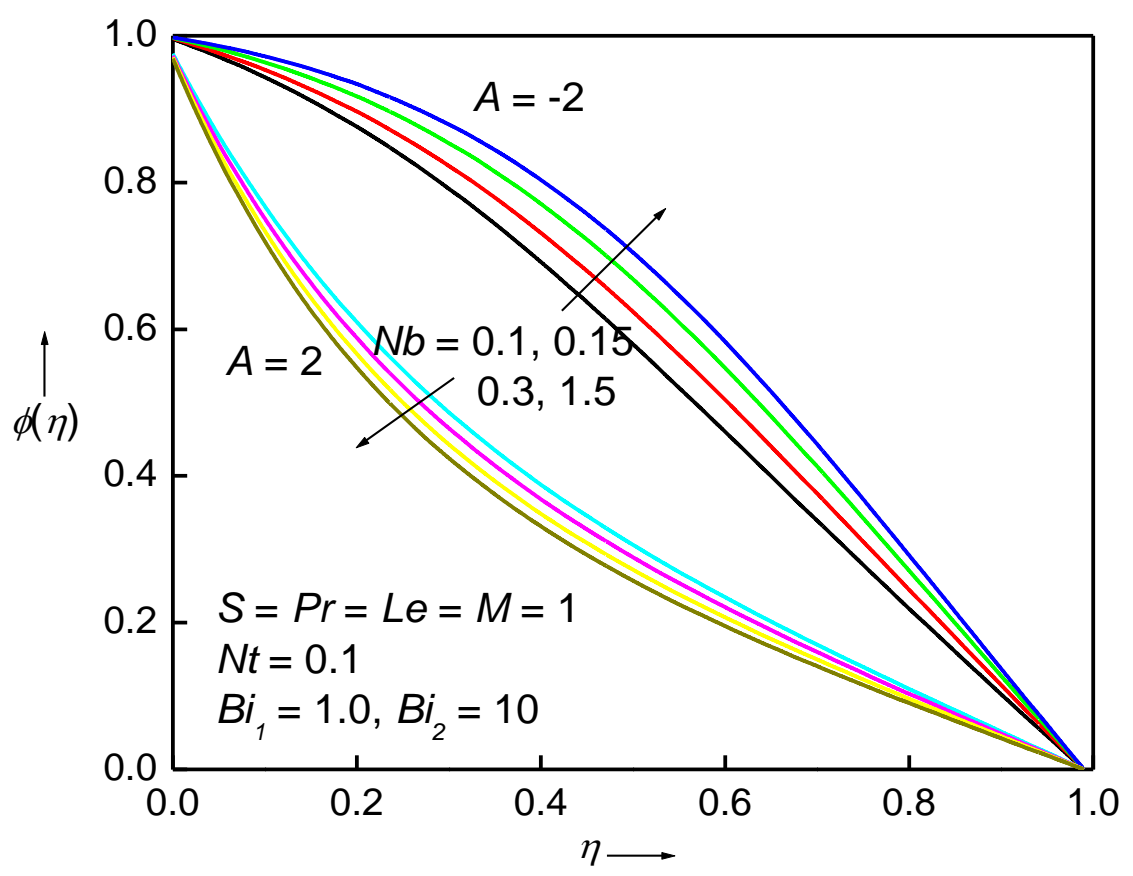

Figure 6b. Influence of $N b$ on $\phi(\eta)$ for unequal Biot numbers. 


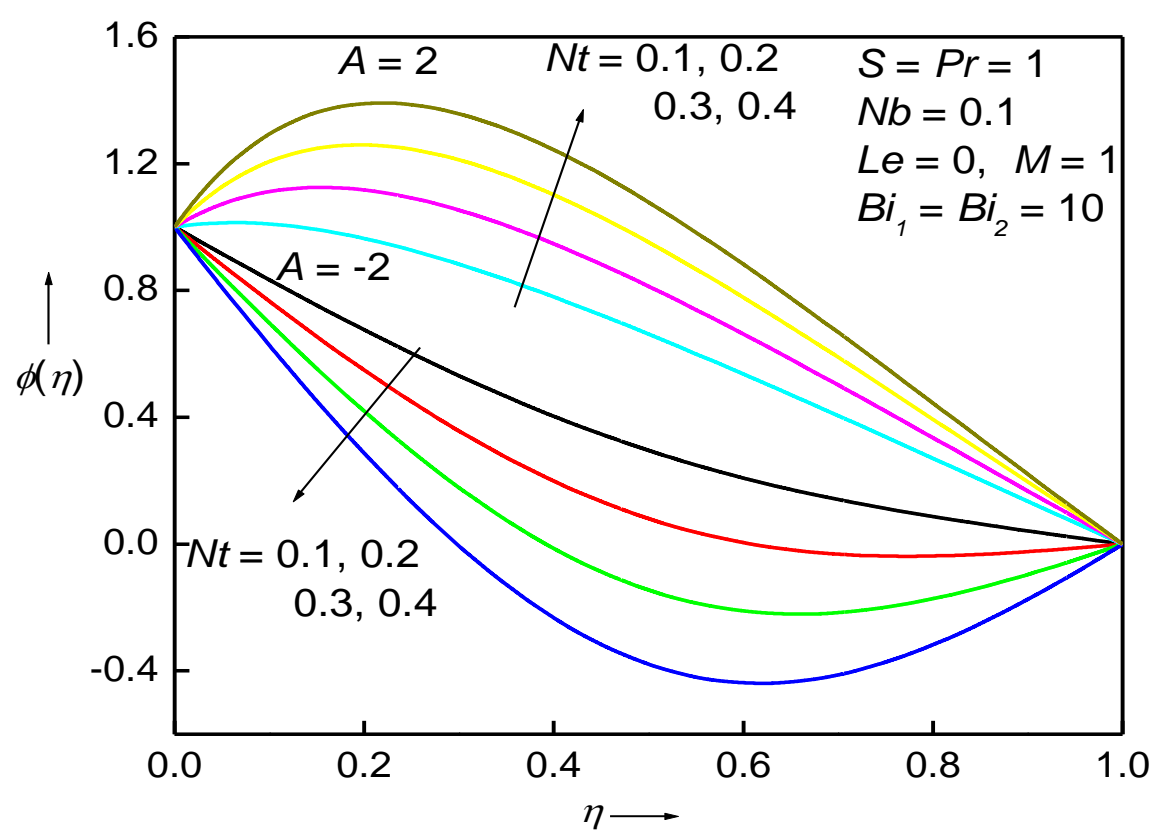

Figure 7a. Influence of $N t$ on $\not(\eta)$ for equal Biot numbers.

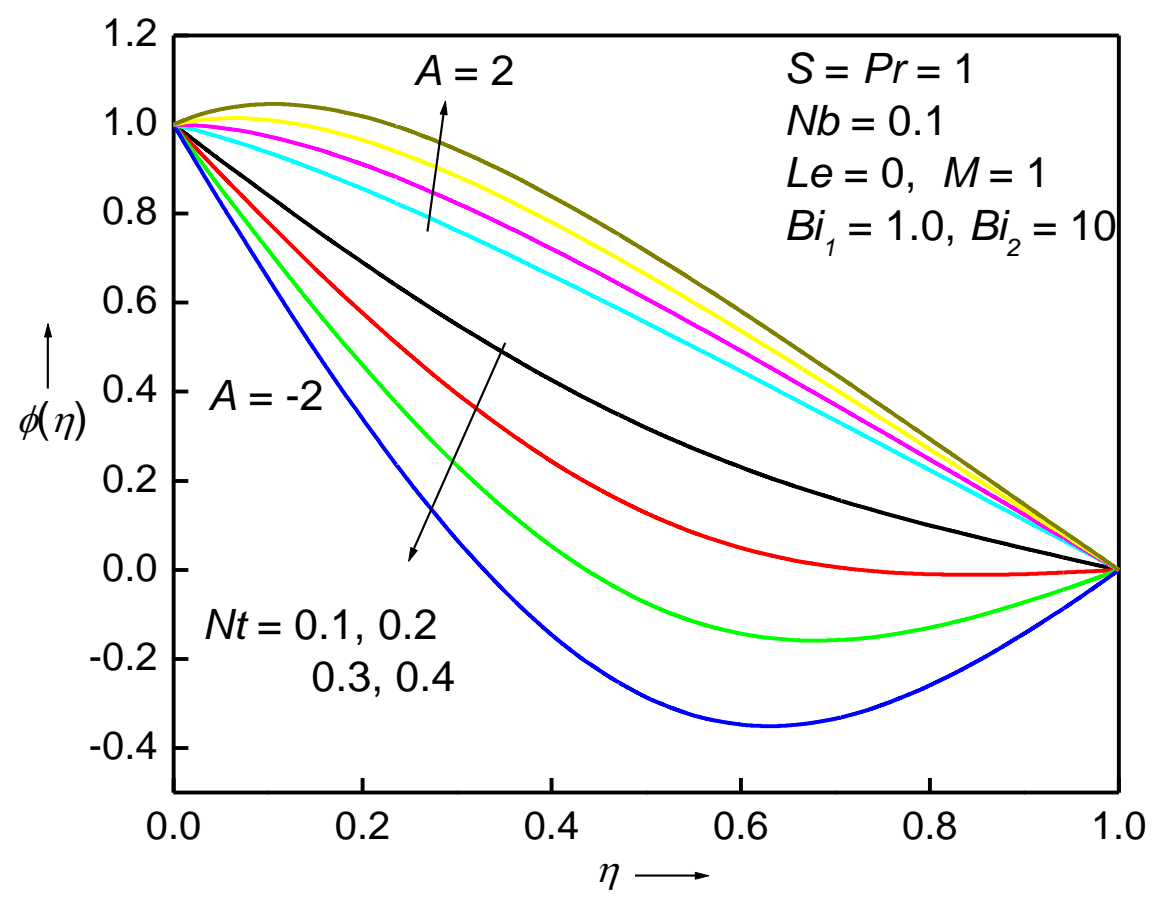

Figure $7 \mathrm{~b}$. Influence of $N t$ on $\phi(\eta)$ for unequal Biot numbers. 


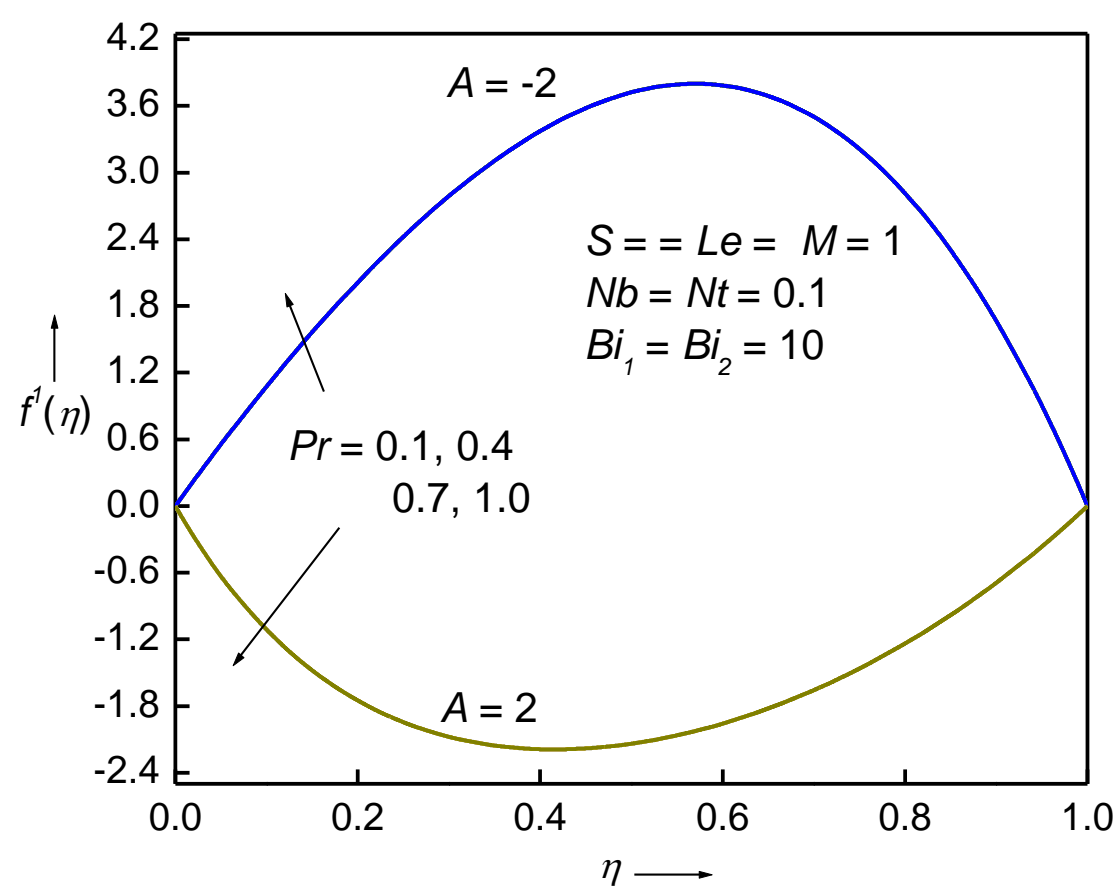

Figure 8a. Influence of $\operatorname{Pr}$ on $f^{l}(\eta)$ for equal Biot numbers.

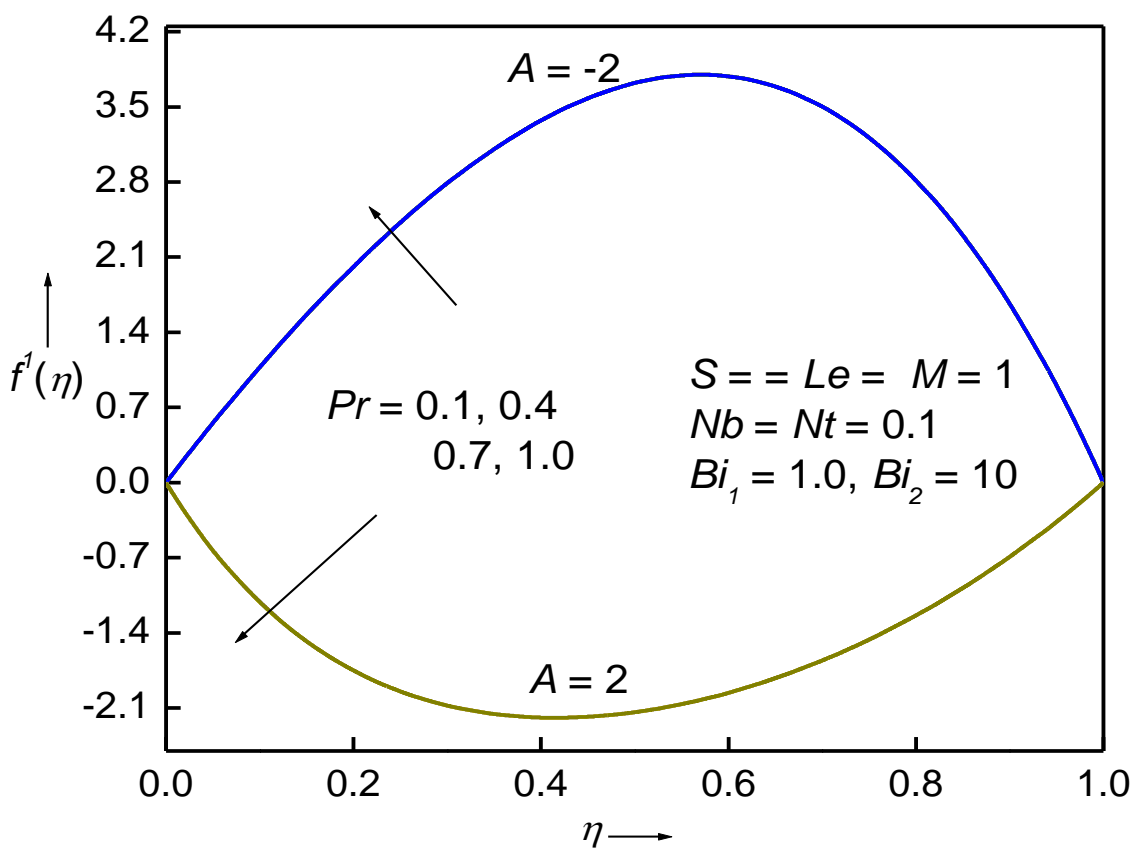

Figure 8 b. Influence of $\operatorname{Pr}$ on $f^{l}(\eta)$ for unequal Biot numbers. 


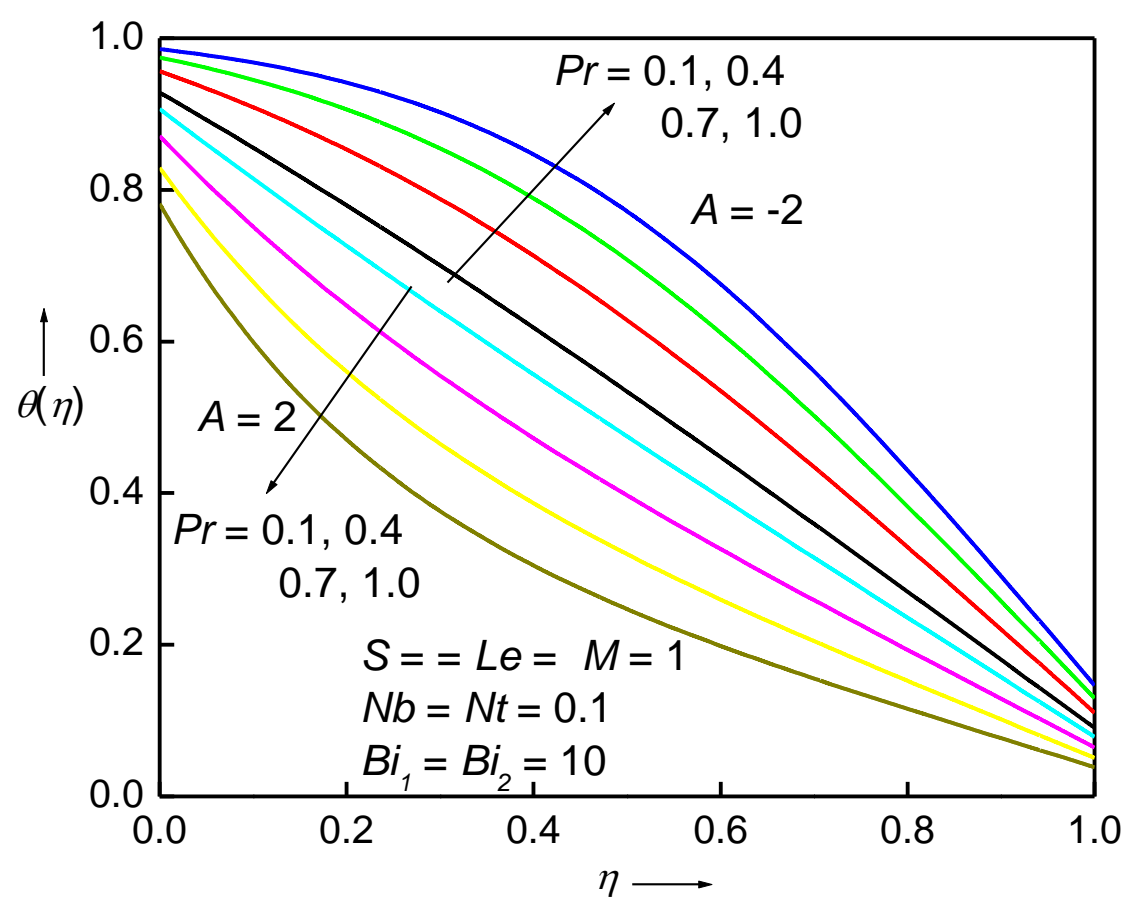

Figure 9a. Influence of $\operatorname{Pr}$ on $\theta(\eta)$ for equal Biot numbers.

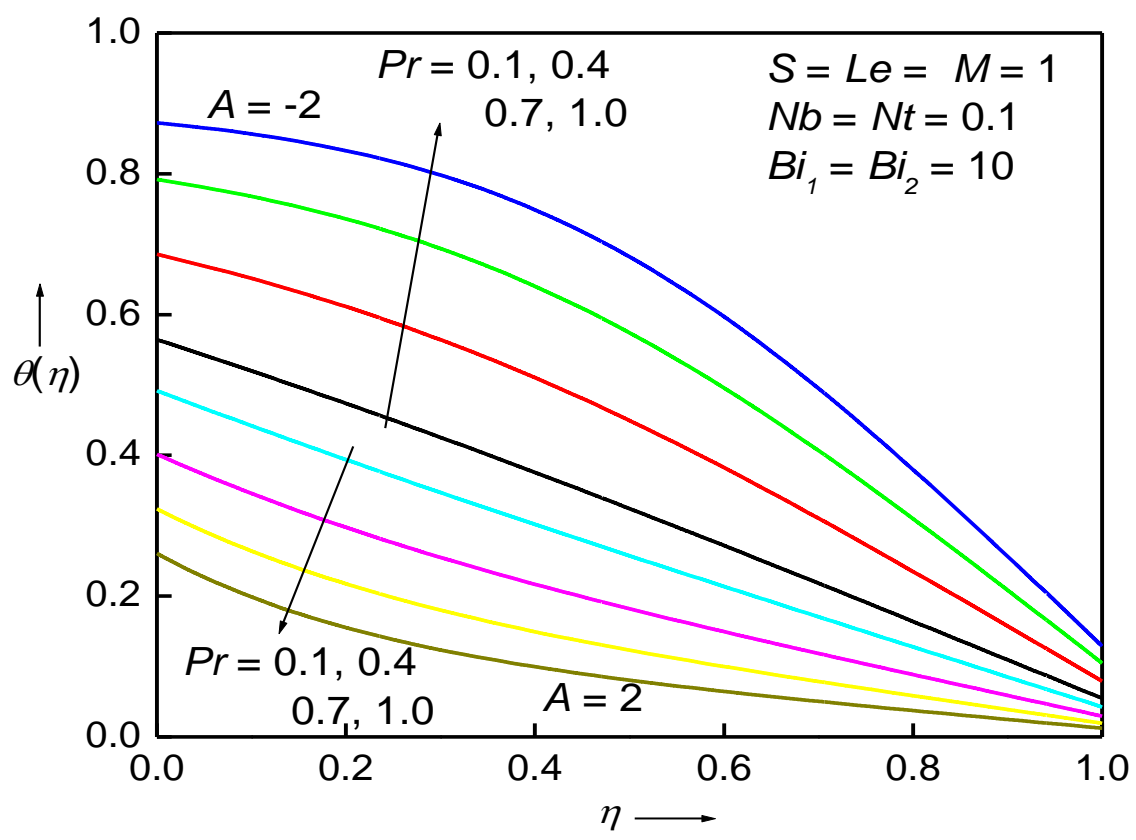

Figure 9b. Influence of $\operatorname{Pr}$ on $\theta(\eta)$ for unequal Biot numbers. 


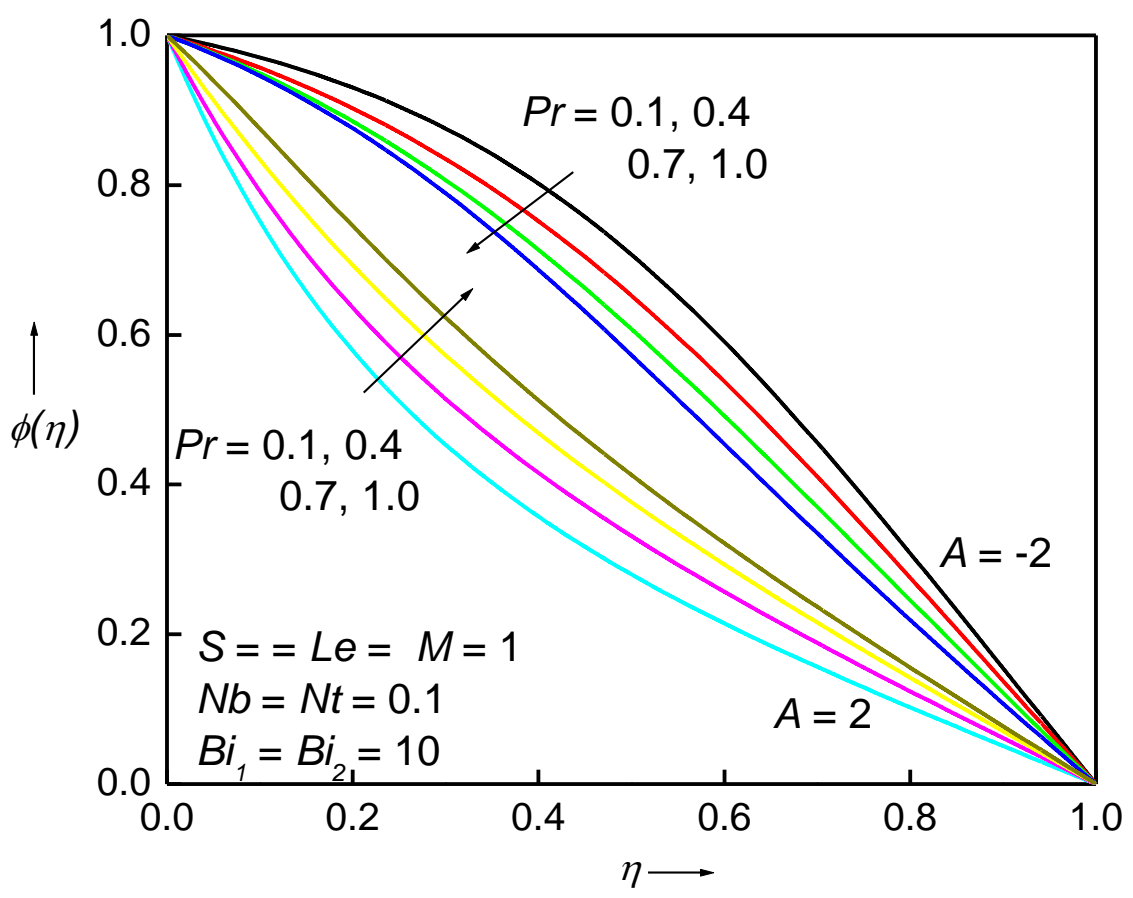

Figure 10a. Influence of $\operatorname{Pr}$ on $\phi(\eta)$ for equal Biot numbers.

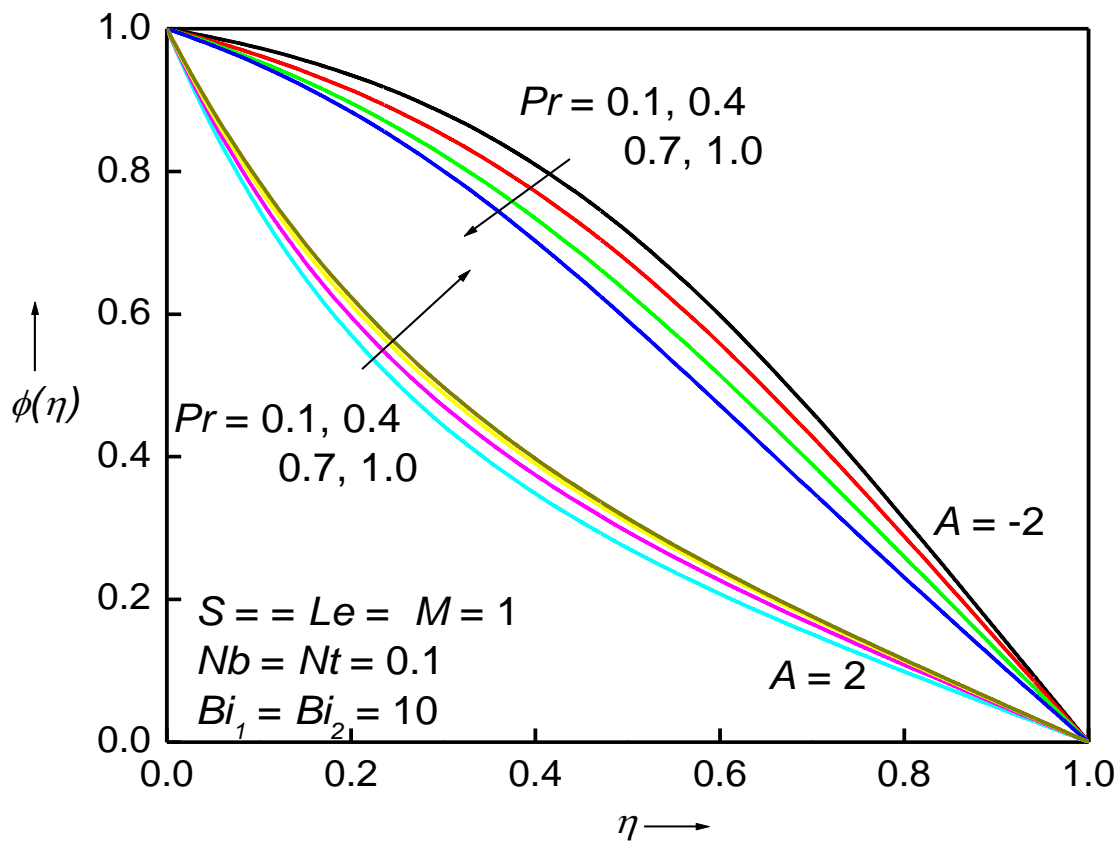

Figure 10b. Influence of $\operatorname{Pr}$ on $\phi(\eta)$ for unequal Biot numbers. 


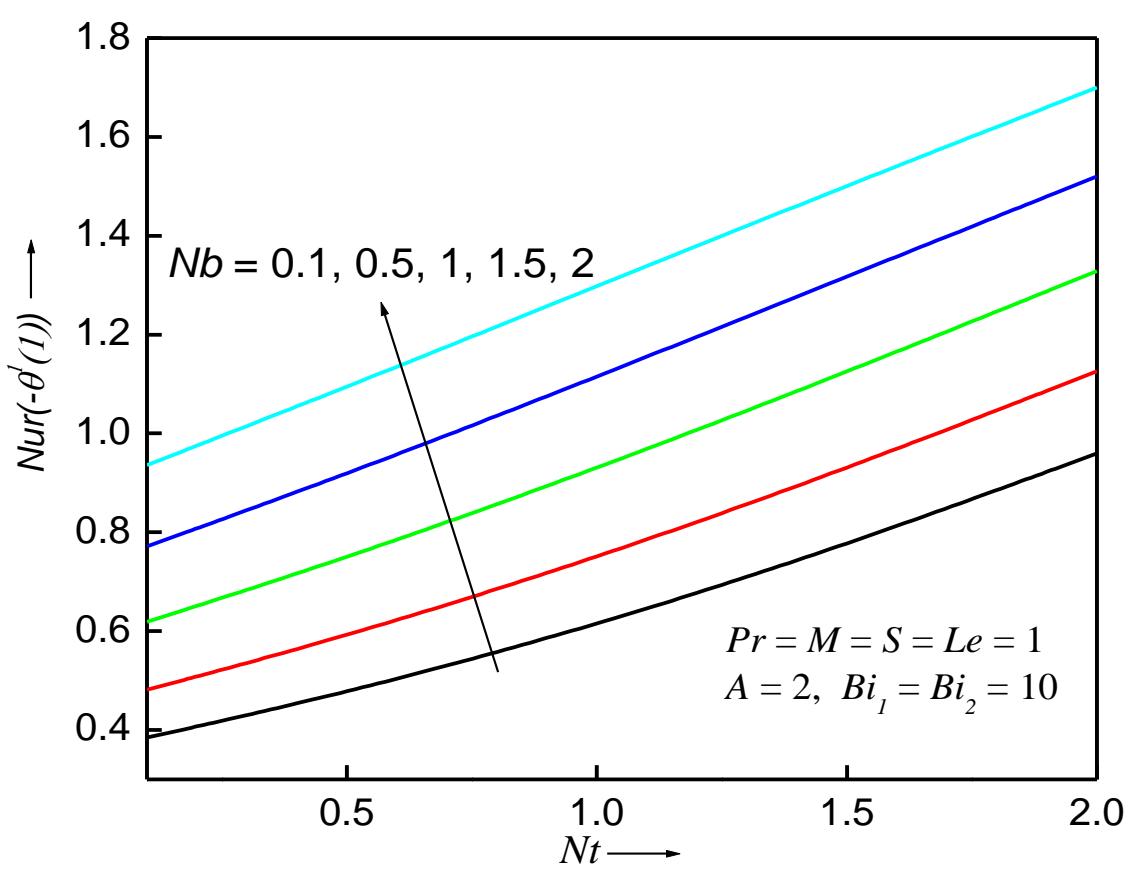

Figure 11a. Influence of $N b$ and $N t$ on $N u r$ for equal Biot numbers.

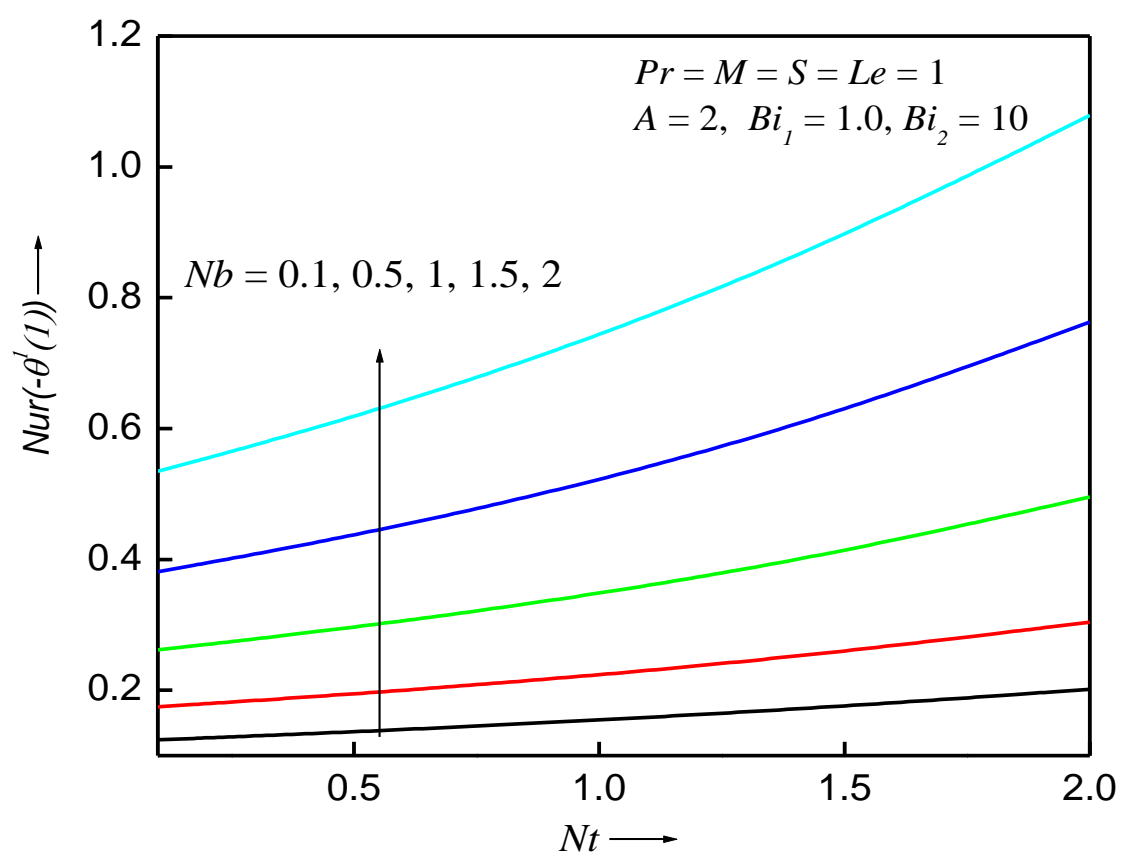

Figure 11b. Influence of $N b$ and $N t$ on $N u r$ for unequal Biot numbers. 


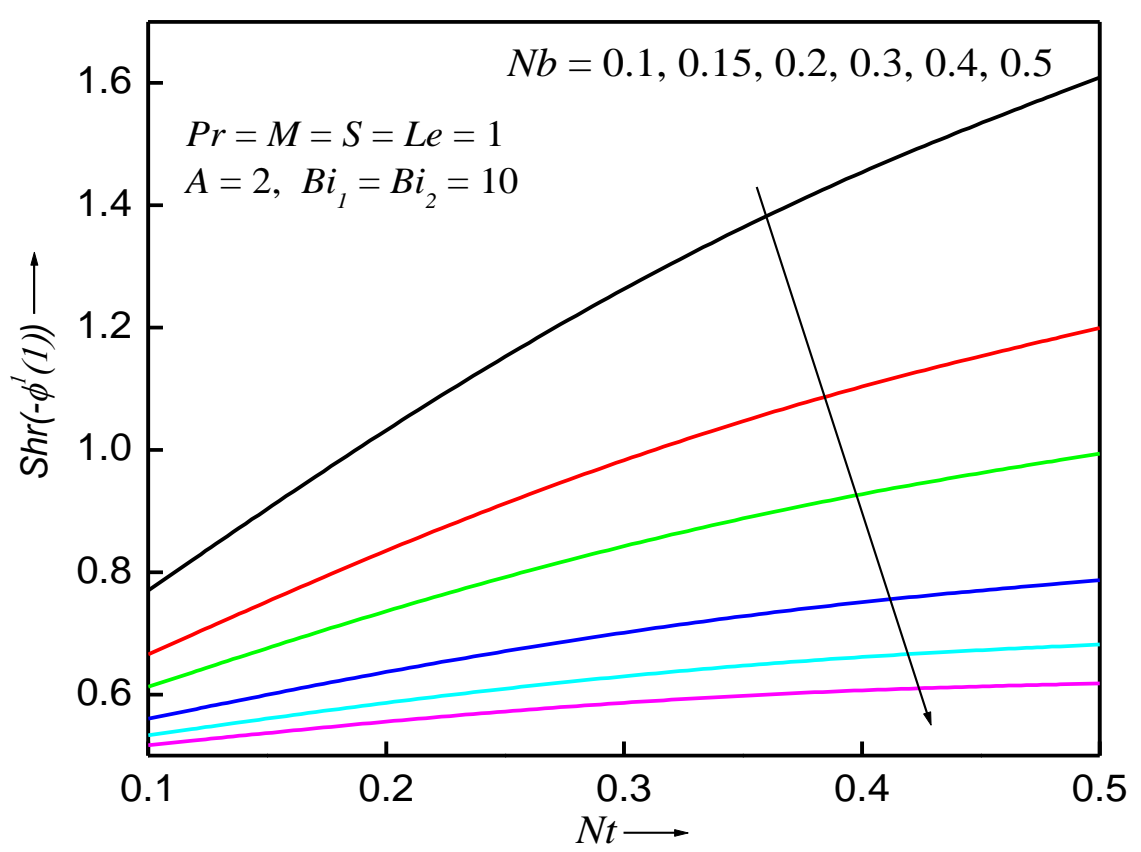

Figure 12a. Influence of $N b$ and $N t$ on $S h r$ for equal Biot numbers.

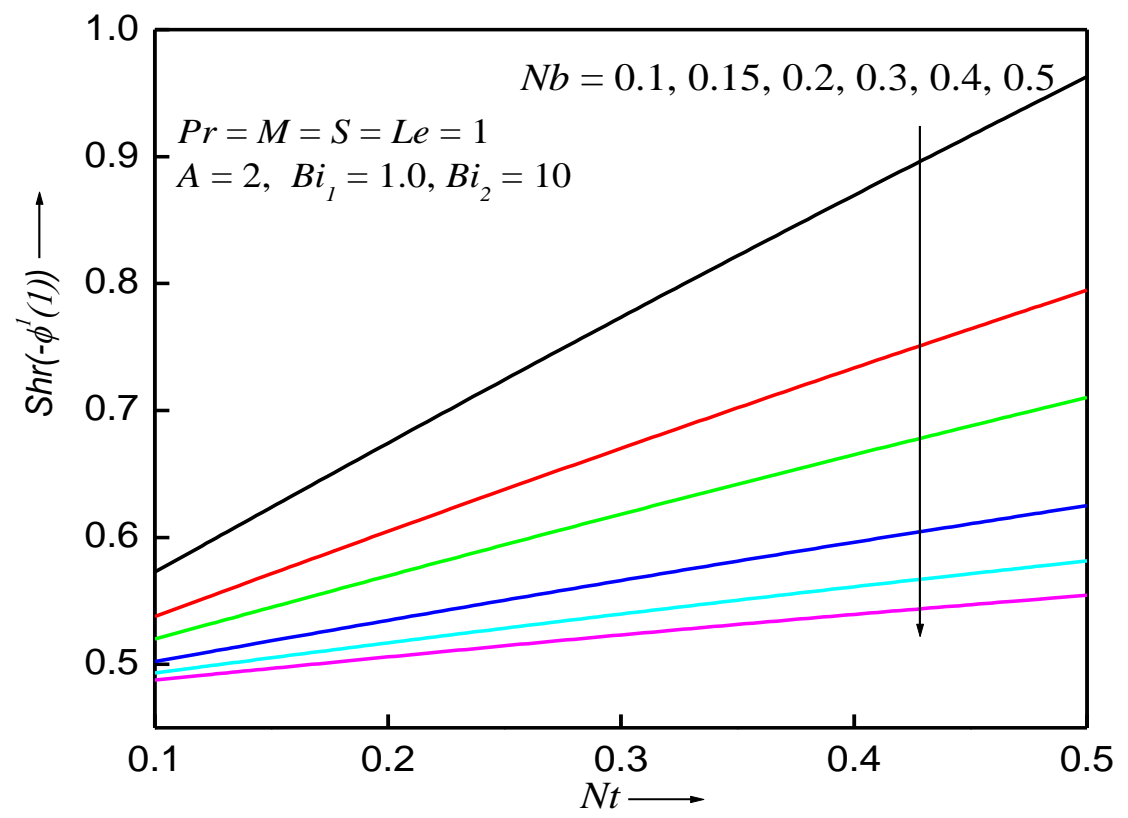

Figure 12b. Influence of $N b$ and $N t$ on $S h r$ for unequal Biot numbers. 
Figures $\mathbf{2 a}$ and $\mathbf{2 b}$ reveal that the velocity profile $\left(f^{\prime}(\eta)\right)$ decreases initially with increasing values of $S$ for the blowing case $(A<0)$ for both equal and unequal Biot numbers (BEUBN) throughout the lower half space $(0 \leq \eta \leq 0.5)$; however a critical point $(\eta \sim 0.55)$ in the upper half space of the gap is reached at which velocity starts increasing with $S$. No slip conditions are enforced at the both disk surfaces $(\eta=0,1)$. The strong blowing at the lower disk takes effect beyond the centre line of the gap $(\eta=0.5)$ which induces acceleration in the upper half space.

For the case $A>0$ (suction at the lower disk), with increased rate of ascent of the lower disk towards the upper disk $(S>0)$ the flow is again retarded i.e. greater negative values are induced in velocity due to the adherence caused between the lower disk surface to the fluid immediately above the disk surface. A more dramatic deceleration ("damping") is therefore generated in the lower half space relative to the case of $A<0$ (blowing) for BEUBN. As with the blowing case ( $A$ $<0)$ subsequently in the upper half space acceleration is produced. There is clearly a redistribution in the momentum which has been identified by other investigators even for Newtonian magnetic lubricants in the absence of nanoparticles, notably Chandrasekhara et al. ${ }^{18}$ and Verma ${ }^{19}$. The asymmetry in profiles is intimately associated with the different disk surface conditions (i.e. transpiration at the lower disk and solid surface at the upper disk). The symmetry may be achieved by setting $A=0$ which makes both disks equivalent (i.e. impervious) with the other data constrained. For $A>0$ (blowing), the velocity maxima are displaced closer to the lower disk as soon as the squeezing parameter, $S$ value is increased; the contrary behavior is computed for $A<0$ (blowing) i.e. the peak velocity migrates towards the upper disk. Velocity profile is skewed towards the lower disk with increasing squeezing number $(S)$ values in the $A<0$ case for BEUBN. It is also noteworthy that the squeezing parameter, $S$, does not have an elementary effect on the lubrication regime. This parameter features in multiple terms in the momentum eqn. (8) and also in the energy eqn. (9), i.e. $-S\left(\eta f^{\prime \prime \prime}+3 f^{\prime \prime}-2 f f^{\prime \prime \prime}\right)$ in the former and $+\operatorname{Pr} S\left(2 f \theta^{\prime}-\eta \theta^{\prime}\right)$ in the latter. The negative sign will inevitably induce retardation i.e. inhibit momentum development and furthermore the complex nonlinear interplay between different order shear terms in the momentum field will contribute to velocity peak shifting in the profiles, as noted earlier by Chandrasekhara et al. ${ }^{18}$. 
Impact of $M$ on $\left(f^{\prime}(\eta)\right)$ field is plotted in Figures 3a and 3b. The value of $M=0$ corresponds to the hydrodynamic i.e. electrically non-conducting nanofluid case. The velocity increases initially with $M$ near the lower disk for the blowing case $(\mathrm{A}<0)$ since lateral mass influx into the regime initially overcomes the retarding Lorentzian magnetic drag force effect. However, in the core zone, the resistive magnetic body force dominates and this manifests in a significant deceleration in the flow with larger $M$ value. In the vicinity of the upper disk there is a weak resurgence in acceleration which again is due to the decaying effect of magnetic field near the disk surface and the re-distribution in momentum further from the core region. A similar observation has been made by Zueco and Bég ${ }^{22}$, even for the rotating disk scenario. The overall implication is that stronger magnetic field only induces deceleration in certain zones of the gap and not continuously across it. It is also apparent that the effect of Hartman number $M$ in proximity to the upper disk is more pronounced as compared to the lower disk for BEUBN.

The significance of $N b$ on $(\theta(\eta))$ is displayed in Figs. $4 \mathrm{a}$ and $4 \mathrm{~b}$ for BEUBN. Here, the temperature profile $(\theta(\eta))$ increases with $N b$ monotonically across the gap i.e. from $\eta=0$ to $\eta=1$. Physically, the haphazard motion of NPs encourages ballistic collisions between nanoparticles, as noted by Buongiorno ${ }^{33}$ which generates additional heating in the magnetic nanofluid, resulting in a boost in the temperature field with larger $N b$ values, that is sustained across the entire gap. The temperature $(\theta(\eta))$ not only significantly rises but is progressively migrated towards the upper disk for both $A>0$ and $A<0$ cases. However substantially greater magnitudes are computed with blowing $(\mathrm{A}<0)$ as compared with suction $(A>0)$ which is the opposite to that encountered in for example external aerodynamic boundary layer flows. The confinement of the lubricant between the disks results in a very different influence from lateral mass flux. It is also pertinent to emphasize that for low $N b$ value (0.1) an approximately linear decay in temperatures is observed from the lower disk to the upper disk. However, with increasing $\mathrm{Nb}$ values, the profile topology warps into a progressively more parabolic form, in particular for the blowing case $(A<0)$. $N b$ features in the energy eqn. (9) in the term $+\operatorname{Pr} N b \theta^{\prime} \phi^{\prime}$ and also in the nanoparticle concentration eqn. (10) in the term, $+\frac{N t}{N b} \theta^{\prime \prime}$. Clearly nanoscale Brownian motion therefore exerts a non-trivial impact on temperature distributions. This heat build-up during lubrication operations can then be sucked out from weep holes via 
appropriate design methods to mitigate thermal damage to the surfaces over prolonged periods. On the other hand, larger metallic magnetic nanoparticles, which correspond to smaller $\mathrm{Nb}$ values, induce cooling in the regime and this is an alternative mechanism for heat regulation in lubrication, as noted by Harta et $a l .{ }^{40}$.

Figures $5 \mathbf{a}$ and $5 \mathbf{b}$ illustrated that the effect of $N t$ on the temperature field $(\theta(\eta))$ for BEUBN. There is a similar response to that computed for $N b$ for both suction and injection; however the magnitudes of temperatures are demonstrably higher and profiles are largely confined to the upper half space of the gap. Increasing thermophoretic body force therefore significantly heats the regime. With unequal Biot numbers (Fig 5b) there is a greater disparity between the temperature profiles for blowing $(A=-2)$ and suction $(A=2)$ as compared to the case of equal Biot numbers (Figure 5a). Much lower temperatures are produced for the suction case in the former (Figure b). Unequal Biot numbers therefore result in significant cooling of the regime for both cases of disk suction or injection, indicating that the inclusion of convective heating boundary conditions incurs a substantial modification in the thermal field. This constitutes a more realistic simulation of actual magnetic lubrication flows and is a novel result in the scientific literature.

The effect of $N b$ and $N t$ on nanoparticle (NP) concentration field $\phi(\eta)$ is depicted in Figures 6a, b and 7a, b respectively, for BEUBN. The NPs concentration field $(\phi(\eta))$ increases with $N b$ due to the haphazard transition of NPs from the upper disk to the nanoliquid. Also there is an increase in the NPs concentration field $(\phi(\eta))$ with thermophoresis parameter $N t$ for the BEUBN. However, in Figures $6 \mathrm{a}, \mathrm{b}$ the profiles are more homogenously constructed whereas in Figures $7 \mathrm{a}, \mathrm{b}$ they are skewed towards the lower disk for suction $(A=2)$ and skewed towards the upper disk for injection $(A=2)$. Asymmetry is prominent in all these figures. Clearly nanoparticle diffusion in the gap is generally enhanced with injection $(A=-2)$ for the unequal Biot number case (Figures $6 \mathrm{a}, \mathrm{b})$ and suppressed with suction $(A=2)$. The converse response is induced for the equal Biot number case (Figures 7a,b). The sensitivity of nanoparticle diffusion to the convective boundary heating is therefore clearly demonstrated. Again these results are novel in the literature and indicate that wall boundary conditions exert a substantial effect not only on thermal diffusion in the gap but also on the migration of nanoparticles away from the disk surfaces and into the core region of the gap. 
In Figures 8a and $\mathbf{8 b}$, the role of $\operatorname{Pr}$, on the velocity $\left(f^{\prime}(\eta)\right)$ field for BEUBN is presented. The Prandtl number effect is minute on the velocity in comparison with the temperature and concentration fields. However, the skewness in velocity profiles is clearly captured. Injection for both equal and unequal Biot numbers is observed to distort the profiles towards the upper disk whereas suction causes a bias towards the lower disk.

The influence of $\operatorname{Pr}$ on $\theta(\eta)$ is depicted in Figures 9a and 9b. There is a distinct elevation in temperature magnitude $(\theta(\eta))$ for the blowing case $(A=-2)$ with greater Prandtl number whereas a significant depletion is induced for the suction case $(A=2)$. Prandtl number is inversely proportionate to thermal conductivity. Higher $\operatorname{Pr}$ for the suction case produces the customary behavior of temperature reduction. However, with blowing present this effect is reversed. These trends are computed for both the equal and unequal Biot number scenarios.

The influence of $\operatorname{Pr}$ on $\phi(\eta)$ is presented in Figures 10a and 10b for BEUBN. The opposite behavior is computed to that for the temperature field. $\phi(\eta)$ magnitudes are diminished with increasing $\operatorname{Pr}$ when injection is present $(A<0)$ whereas they are elevated when suction is present $(A>0)$ for BEUBN. Also, it is noteworthy that while non-zero temperatures are present at the lower and upper disk (Figures 9a, b), consistently vanishing nanoparticle concentration values are present at both disks, irrespective of the Biot number case.

Figures 11a, b and 12a, b displayed that the collective effect of $N b$ and $N t$ on the reduced Nusselt number Nur and the Sherwood Numbers Shr for BEUBN. Increasing values of $\mathrm{Nb}$ and $\mathrm{Nt}$ consistently enhance the magnitude of Nusselt number Nur for BEUBN, although much higher magnitudes are observed for the equal Biot number case (Figure 11a) compared with the unequal Biot number case (Figures 11b). However increasing values of $\mathrm{Nb}$ and $\mathrm{Nt}$ induce the opposite response in Sherwood number for BEUBN i.e. they reduce nanoparticle mass transfer rate to the disk surface; again the magnitudes of Shr are markedly higher for the equal Biot number case (Figure 12a) relative to the unequal Biot number case (Figure 12b). Magnetic nano-lubricants therefore achieve a substantial modification in both heat and mass transfer rate to the disk surface.

Table 1 also presents the behavior of friction coefficient for the variation of squeezing parameter $S$ and Hartmann number $M$. The friction factor clearly decreases for escalating 
positive values of squeezing parameter $S$ i.e., when the lower disk ascends. However, the friction factor is enhanced with stronger magnetic Lorentz force relative to viscous force $(M>1)$ for BEUBN.

\section{CONCLUSIONS}

A comprehensive mathematical model has been derived for the unsteady squeezing flow of a magnetic (smart) Newtonian nano-lubricant between two parallel disks under an axial magnetic field. The lower disk is permeable whereas the upper disk is solid. Using the Buongiorno nanoscale model, both thermophoretic body force and haphazard motion effects are included. Robin (mixed) boundary conditions are imposed at both disks. A detailed examination of the key thermophysical parameters on transport characteristics is conducted. Skin friction solutions have been verified with earlier homotopy solutions ${ }^{43}$ in the absence of Robin boundary conditions. The principal findings of the current simulations may be summarized as follows:

- The friction factor is enhanced with Hartmann number (i.e. stronger magnetic field).

- An intensification in Brownian motion magnitude (i.e. exacerbation in haphazard motion of nanoparticles) manifests in a substantial temperature enhancement.

- Higher thermophoretic parameter also elevates temperatures in the regime.

- The nanoparticles concentration at the disk is boosted with higher values of Brownian motion parameter.

- The response of temperature is similar in both suction and injection cases, however this tendency is quite opposite for nanoparticles concentration.

- The results are qualitatively similar for equal and unequal Biot numbers, although skewness of velocity profiles is different with suction or injection present.

- Increasing Brownian motion and thermophoresis parameters elevate Nusselt number magnitudes although higher values are computed for the equal Biot number case compared with the unequal Biot number case. 
- Brownian motion and thermophoresis parameters reduce Sherwood number and again magnitudes are markedly higher for the equal Biot number case relative to the unequal Biot number case.

- Unequal Biot numbers produce significant cooling of the regime for both cases of disk suction or injection, indicating that Robin boundary conditions yield substantial deviation from thermal boundary conditions employed in simpler squeezing lubrication models.

The present analysis has neglected disk rotation, viscous heating, Ohmic dissipation and entropy generation $^{73}$ aspects. These may be considered in the future. Furthermore, non-Newtonian characteristics of the magnetic nano-lubricant have also been ignored. Subsequent studies may address micropolar ${ }^{69}$ and other rheological models of relevance to tribological systems.

\section{REFERENCES}

1. Marrero V, Borca-Tasciuc DA and Tichy J. On squeeze film damping in Microsystems. Journal of Tribology 2010; 132: 03170-031707.

2. Mac DonnchadhaV, Leal $\mathrm{C}$ and Esmonde H. Oscillatory squeeze film analysis of soft Contact lenses. Contact Lens and Anterior Eye 2018; 41: 377-388.

3. Bég O. Anwar, Jouri WS, Beg TA, Kadir Ali, Leonard HJ, MD Shamshuddin and Hung TK. Computation of asymmetric micropolar squeezing flow in a bionic prosthetic dual disk system with blowing (injection) and Reynolds number effects. Int. Conf. Advances in Mathematics, Physics \& Applied Science (ICAMPA) 2020.

4. San Andres LA and Vance JM. Effect of fluid inertia on the performance of squeeze film damper supported rotors, ASME J. Engineering for Gas Turbine and Power 1988; 110: 51-58.

5. Medley JB, Dowson D and Wright V. Transient elastohydrodynamic lubrication models for the human ankle joint. Engineering in Medicine 1984; 13: 137-151.

6. Stefan MJ. Versuch Uber die scheinbare adhesion. Sitzungsberichte der Akademieder Wissenschaften in Wien. Mathematic-Naturwissen 1874; 69: 713-72.

7. Reynolds O. On the theory of lubrication and its application to Mr. Beauchamp tower's experiments, including an experimental determination of the viscosity of olive oil. Philosophical transactions of the Royal Society of London 1886; 177: 157-234. 
8. Archibald FR. Load capacity and time relations for squeeze films. Trans. ASME 1965; 78: A231-A245.

9. Grimm RJ. Squeezing flows of Newtonian liquid films an analysis including fluid Inertia. Applied Scientific Research 1976; 32: 149-166.

10. Storace A and Cline S. NASA-General Electric Energy Efficient Engine high load squeeze film damper-system analysis and test results. In $20^{\text {th }}$ Joint Propulsion Conference 1984; 12-17.

11. Ishizawa S. The unsteady laminar flow between two parallel discs with arbitrarily varying gap width. Bulletin of JSME 1966; 9: 533-550.

12. Burrows CR, Sahinkaya MN and Kucuk NC, A new model to predict the behavior of cavitated squeeze-film bearings. Proc. of the Royal Society of London, Mathematical and Physical Sciences 411 (1841) 445-466.

13. Allaire PE, Barrett LE and Gunter EJ. Variational method for finite length squeeze film damper dynamics with applications. WEAR 1977; 42: 9-22.

14. Hamdan MH and Barron RM. Analysis of the squeezing flow of dusty Fluids.Applied Scientific Research 1992; 49: 345-354.

15. Della Pietra L and Adiletta G, The squeeze film damper over four decades of investigations. Part I: Characteristics and operating features. The Shock and Vibration Digest 2002; 34: 3-26.

16. Lin JR, Chu LM, Hung CR and Lu RF. Magneto-hydrodynamic Non-Newtonian curved circular squeeze films. J. of Marine Sci. and Technology 2014; 22: 566-571.

17. Hughes WF and Elco RA. Magnetohydrodynamic lubrication flow between parallel rotating disks. J. of Fluid Mechanics 1962; 13: 21-32.

18. Chandrasekhara BC, Kantha R and Rudraiah N. Effect of slip on porous-walled squeeze films in the presence of a transverse magnetic field. Appl. Scientific Research 1978; 34 : 393- 411.

19. Verma PDS. Magnetic fluid-based squeeze film. Int. J. of Engng. Sci. 1986; 24: 395401.

20. Siddiqui AM, Irum S and Ansari AR. Unsteady squeezing flow of a viscous MHD fluid between parallel plates, a solution using the homotopy perturbation method. Mathematical Modeling and Analysis 2008; 13: 565-576. 
21. Ghadikolaei SS, Hosseinzadeh K and Ganji DD. Analysis of unsteady MHD EyringPowell squeezing flow in stretching channel with considering thermal radiation and Joule heating effect using AGM. Case studies in thermal engineering 2017; 10: 579-594.

22. Zueco J and Bég O. Anwar. Network numerical analysis of hydromagnetic squeeze film flow Dynamics between two parallel rotating disks with induced magnetic field effects. Tribology International 2010; 43: 532-543.

23. Mahanthesh B. Gireesha BJ, Thammanna GT, Hayat T and Alsaedi A. Magnetohydrodynamic squeezing two-phase flow of particulate suspension in a rotating channel with transpiration cooling. Proceedings of the Institution of Mechanical Engineers. Part C: Journal of Mechanical Engineering 2019; 233: 1224-1235.

24. Bég O. Anwar, Tripathi D, Sochi T and Gupta PK. Adomian decomposition method (ADM) simulation of magneto-bio-tribological squeeze film with magnetic induction effects. Journal of Mechanics in Medicine and Biology 2015; 15: 1550072.

25. Hayat T, Yousaf A, Mustafa M and Obaidat S. MHD squeezing flow of second grade fluid between two parallel disks. Int. J. Numerical Methods in Fluids 2012; 69: 399-410.

26. Shamshuddin MD, Mishra SR, Kadir A and Bég O. Anwar. Unsteady chemotribological squeezing flow of magnetized bioconvection lubricants: numerical study. J. of Nanofluids 2019; 8: 407-419.

27. Arain MB, Bhatti MM, Zeeshan A, Saeed T and Hobiny A. Analysis of Arrhenius kinetics on multiphase flow between a pair of rotating circular plates. Mathematical Problems in Engineering 2020; 2020: ID 2749105.

28. Kezzar M, Tabet I and Nafir N, Semi-analytical and numerical solutions for nonlinear problem of unsteady squeezing ferro-fluid flow between stretchable/shrinkable walls under external magnetic field and thermal radiation using differential transformation. J. of Nanofluids 2019; 8: 297-307.

29. Bég O. Anwar, Bég TA and Kadir A. Computation of multi-physical squeezing in electromagnetic actuators for seismic structural damping control applications with the variational parameter method. ICGESS 2021: 15th International Conference on Green Energy and Smart Systems, Cairo, Egypt 2021; 13-14. 
30. Zhang L, Bhatti MM and Michaelides EE. Electro-magnetohydrodynamics flow and heat transfer of a third-grade fluid using a Darcy- Brinkman-Forchheimer model, Int. J. Num. Methods for Heat and Fluid Flow 2020; DOI: 10.1108/HFF-09-2020-0566

31. Shahid A, Huang HL, Khalique CM and Bhatti MM. Numerical analysis of activation energy on MHD nanofluid flow with exponential temperature-dependent viscosity past a porous plate, Journal of Thermal Analysis and Calorimetry, 2020. https://doi.org/10.1007/s10973-020-10295-9

32. Choi SUS. Enhancing thermal conductivity of fluids with nanoparticles. FED 231/MD; ASME: New York, NY, USA 1995.

33. Buongiorno J. Convective transport in nanofluids. ASME J. Heat Transfer 2006; 128: 240-250.

34. Hwang Y, Park HS, Lee JK and Jung WH. Thermal conductivity and lubrication characteristics of nanofluids. Current Applied Physics 2006; 6: e67-e71.

35. Chen Y, Renner P and Liang H, Dispersion of nanoparticles in lubricating oil: a critical review, Lubricants 2019; 7: 1-21.

36. Ghaednia H, Jackson RL and Khodadadi JM. Experimental analysis of stable $\mathrm{CuO}$ nanoparticle enhanced lubricants. J. of Experimental Nanoscience 2015; 10: (2015) 1-18.

37. Bég O. Anwar, Espinoza DS, Kadir A., MD Shamshuddin and Sohail A. Experimental study of improved rheology and lubricity of drilling fluids enhanced with nano-particles. Applied Nanoscience 2018; 8: 1069-1090.

38. Pendleton A, Kar P, Kundu S, Houssamy S and Liang H, Effects of nanostructured additives on boundary lubrication for potential artificial joint applications, J. of tribiology 2010; 132: 031201 (5 pages).

39. Nicoletti R. The importance of the heat capacity of lubricants with nanoparticles in the static behavior of journal bearings. J. of tribology 2014; 136: 044502 (5 pages).

40. Harta IC, Owens K, De Jesus Santiago S, Schall D, Thrush S, Barber G and Zou Q, Tribological performance of $\mathrm{ZnO}$-oil nanofluids at elevated Temperatures. SAE Int. J. of Fuels and Lubricants 2013; 6: 126-131.

41. Wu YY, Tsui WC and Liu TC. Experimental analysis of tribological properties of lubricating oils with nanoparticle additives. Wear 2007; 262: 819-825. 
42. Hu ZS, Lai R, Lou F, Wang LG, Chen ZL, Chen GX and Dong JX. Preparation and tribological properties of nanometer magnesium borate as lubricating oil additive, Wear 2002; 252: 370-374.

43. Hashmi MM, Hayat T, Alsaedi A, On the analytic solutions for squeezing flow of nanofluid between parallel disks. Nonlinear Analysis: Modelling and Control 2012; 17: 418- 430 .

44. Das K, Jana S, Acharya N, Slip effects on squeezing flow of nanofluid between two parallel disks. Int. J. of App. Mech. and Enging 2016; 21: 5-20.

45. Dib A, Haiahem A and Bou-Said B. Approximate analytical solution of squeezing unsteady nanofluid flow. Powder technology 2015; 269: 193-199.

46. Khan SU, Al-Khaled K and Bhatti MM. Bioconvection analysis for flow of Oldroyd-B nanofluid configured by a convectively heated surface with partial slip effects. Surfaces and Interfaces 2021; 23: 100982.

47. Hosseinzadeh Kh, Roghani So, Asadi A, Mogharrebi A and Ganji DD. Investigation of micropolar hybrid ferrofluid flow over a vertical plate by considering various base fluid and nanoparticle shape factor, Int. J. of Num. Methods for Heat and Fluid Flow, 2020; DOI 10.1108/HFF-02-2020-0095.

48. Rostami AK, Hosseinzadeh Kh and Ganji DD. Hydrothermal analysis of ethylene glycol nanofluid in a porous enclosure with complex snowflake shaped inner wall. Waves in Random and Complex Media 2020; DOI 10.1080/17455030.2020.1758358.

49. Hosseinzadeh Kh, Roghani So, Mogharrebi AR, Asadi A, Waqas M and Ganji DD. Investigation of cross-fluid flow containing motile gyrotactic microorganisms and nanoparticles over a three-dimensional cylinder. Alexandria Engineering Journal 2020; 59:3297-3307.

50. Lineira del Rio JM, Lopez ER, Gonzalez Gomez M, Yanez Vilar S, Pineiro Y, Rivas J and Fernandez J. Tribological behavior of nanolubricants based on coated magnetic nanoparticles and trimethylolpropane trioleate base oil. Nanomaterials 2020; 10: 683.

51. Ghandoor HEl, Zidan HM, Khalil MM and Ismail MIM. Synthesis and some physical properties of magnetite (Fe3O4) nanoparticles. Int. J. Electrochem. Sci. 2012; 7: 57345745. 
52. Zhou G, Zhu Y, Wang X, Xia M, Zhang Y and Ding H. Sliding tribological properties of $0.45 \%$ carbon steel lubricated with $\mathrm{Fe} 3 \mathrm{O} 4$ magnetic nano-particle additives in base oil, Wear 2013; 301: 753-757.

53. Kotia A, Rajkhowa P, Rao GS and Ghosh SK. Thermophysical and tribological properties of nanolubricants: A review, Heat and Mass Transfer 2018; 54: 3493-3508.

54. Bég O. Anwar, Sohail A, Kadir A and Bég TA. B-spline collocation simulation of nonlinear transient magnetic nanobio-tribological squeeze-film flow. J. Mechanics in Medicine Medicine and Biology 2018; 18: 1850007.

55. Hosseinzadeh Kh, Moghaddam MAE, Asadi A, Mogharrebi AR, Jafari B, Hasani MR and Ganji DD. Effect of two different fins (longitudinal-tree like) and hybrid nanoparticles $\left(\mathrm{MoS}_{2}-\mathrm{TiO}_{2}\right)$ on solidification process in triplex latent heat thermal energy storage system. Alexandria Engineering Journal 2021; 60: 1967-1979

56. Lahmar S, Kezzar M, Eid MR and Sari MR. Heat transfer of squeezing unsteady nanofluid flow under the effects of an inclined magnetic field and variable thermal conductivity. Physica A: Statistical Mechanics and its Applications 2020; 540: 123138.

57. Ahmed N, Khan U and Mohyud-Din ST. Influence of thermal radiation and viscous dissipation on squeezed flow of water between Riga plates saturated with carbon nanotubes Colloids and Surfaces. A: Physicochemical and Engineering Aspects 2017; 522: 389-398.

58. Vajravelu K, Prasad KV, Ng CO, Vaidya H. MHD squeeze flow and heat transfer of a nanofluid between parallel disks with variable fluid properties and transpiration. Int. J. of Mechanical and Materials Engineering 2017; 12: 2-14.

59. Hosseinzadeh Kh, Moghaddam MAE, Asadi A, Mogharrebi AR and Ganji DD. Effect of internal fins along with hybrid nanoparticles on solid process in star shape triplex latent heat thermal energy storage system by numerical simulation. Renewable Energy 2020; 154: 497-507.

60. Aziz A. A similarity solution for laminar thermal boundary layer over a flat plate with a convective surface boundary condition. Comm. in Nonlinear Sci. and Numerical Simulation 2009; 14: 1064-1068.

61. Uddin MJ, Bég O. Anwar and Amin N. Hydromagnetic transport phenomena from a stretching or shrinking nonlinear nanomaterial sheet with Navier slip and convective 
heating: a model for bio-nano-materials processing. J. of Magnetism and Magnetic Materials 2014; 368: (2014) 252-261.

62. Pattnaik PK, Mishra SR, Mahanthesh B, Gireesha BJ and Rahimi-Gorji M. Heat transport of nano-micropolar fluid with an exponential heat source on a convectively heated elongated plate using numerical computation. Multidiscipline Modeling in Materials and Structures 2020; doi.org/10.1108/MMMS-12-2018-0222.

63. Uddin MJ, Bég O. Anwar and Uddin MN. Energy conversion under conjugate conduction, magneto-convection, diffusion and nonlinear radiation over a non-linearly stretching sheet with slip and multiple convective boundary conditions. Energy 2016; 115: 1119-1129.

64. Hosseinzadeh Kh, Roghani So, Mogharrebi1 AR, Asadi1 A and Ganji DD. Optimization of hybrid nanoparticles with mixture fluid flow in an octagonal porous medium by effect of radiation and magnetic field. Journal of Thermal Analysis and Calorimetry 2020; DOI 10.1007/s 10973-020-10376-9.

65. Hosseinzadeh Kh, Asadi A, Mogharrebi AR, Azari ME and Ganji DD. Investigation of mixture fluid suspended by hybrid nanoparticles over vertical cylinder by considering shape factor effect. Journal of Thermal Analysis and Calorimetry 2020; DOI 10.1007/s10973-020-09347-X

66. Umavathi JC and Veershetty S. Non-Darcy mixed convection in a vertical porous channel with boundary conditions of third kind. TIPM 2012; 95: 111-131.

67. Umavathi JC and Bég O. Anwar. Numerical study of double-diffusive dissipative reactive convective flow in an open vertical duct containing a non-Darcy porous medium with Robin boundary conditions. J. Eng. Math 2019; 119: 135-147.

68. Umavathi JC and Bég O. Anwar. Mathematical modeling of triple diffusion in natural convection flow in a vertical duct with robin boundary conditions, viscous heating and chemical reaction effects. J. of Engineering Thermophysics 2020; 29: 1-26.

69. Umavathi JC and Sultana J. Mixed convective flow of a micropolar fluid mixture in a vertical channel with boundary conditions of the third kind. J. of Engineering Physics and Thermophysics 2012; 85: 895-908. 
70. Zohra FT, Uddin MJ, Ismail AIM, Bég O. Anwar and Kadir A, Anisotropic slip magneto-bioconvection flow from a rotating cone to a nanofluid with Stefan lowing effects. Chinese journal of physics 2018; 56: 432-448.

71. Uddin MJ, Kabir MN, Alginahi Y and Bég O. Anwar. Numerical solution of bio-nano convection transport from a horizontal plate with blowing and multiple slip effects. Proceedings of the Institution of Mechanical Engineers, Part C: Journal of Mechanical Engineering Science 2019; 233: 6910-6927.

72. Bég O. Anwar, Uddin MJ, Bég TA, Kadir A, Shamshuddin M and Babaie M. Modelling mass transfer from a rotating cone in anisotropic porous media with Stefan blowing and Navier slip. Indian J. Physics 2019; doi.org/10.1007/s12648-019-01520-9 (16 pages).

73. Dawar A, Shah Z, Khan W, Idrees M and Islam S. Unsteady squeezing flow of magnetohydrodynamic carbon nanotube nanofluid in rotating channels with entropy generation and viscous dissipation. Advances in Mechanical Engineering 2019; 11: 1687814018823100. 